C2020. This manuscript version is made available under the CC-BY-NC-ND 4.0 license http://

creativecommons.org/licenses/by-nc-nd/4.0/

\title{
Building integrated solar concentrating systems: A review
}

\author{
Guiqiang Li ${ }^{\mathrm{a}, *}$ guiqiang.li@hull.ac.uk, Qingdong Xuan ${ }^{\mathrm{b}}$, M.W. Akram ${ }^{\mathrm{c}}$, Yousef Golizadeh Akhlaghi ${ }^{\mathrm{a}}$, Haowen Liư ${ }^{\mathrm{a}}$, Samson Shittu ${ }^{\mathrm{a}}$

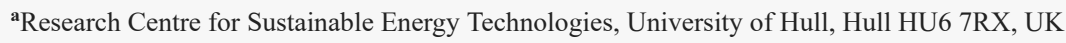 \\ ${ }^{b}$ Department of Thermal Science and Energy Engineering, University of Science and Technology of China, 96 Jinzhai Road, Hefei City 230026, China \\ 'Department of Precision Machinery and Instrumentation, University of Science and Technology of China, 96 JinzhaiRoad, Hefei, Anhui 230026, China \\ *Corresponding author.
}

\begin{abstract}
In the building sector, concerns towards the vast energy consumption has promoted the development of renewable energy technologies. In this regards, the solar concentration devices show a promising concept for building applications. However, the solar concentrators for application in buildings have many restrictions, which are different from the traditional solar concentrators. The main objective of this paper is to present a concise review on the building integrated concentrating devices, that have their own characteristics and multiple functions. This paper made a classification based on device's functions, i.e. building integrated concentrated photovoltaic systems (BICPV), building integrated concentrating solar thermal (BICST) and building integrated concentrating solar daylighting (BICSD) and the combination of functions, i.e. BICPV/T, BICPV/D, BICST/D and $\mathrm{BICPV/T/D}$. At the same time, this paper presented an elaborate introduction of the demands, types and applications of the building integrated concentrating devices and prospects/ directions/ policies about these technologies around the world. The review would provide important information for the actual engineering of building integrated concentrating devices.
\end{abstract}

Keywords: Solar concentrating systems; Building integrated; PV; Solar thermal; Daylighting

\section{Nomenclature}

ASF

ACPC

BICPV

BICPT

BICSD

$\mathrm{BICPV} / \mathrm{T}$

BICPV/D

$\mathrm{BICPT} / \mathrm{D}$

BICPV/T/D

CCPC

$\mathrm{CPC}$

CPV

$\mathrm{dCCPC}$

LFP

LCA

LCIA

LSC

MSDTIRC

MPPT

MCRTM)

MCPV

(PCM)

PRIDE

RASF

SEH

TIR

WICPV

\author{
Adaptive Solar Façade \\ Asymmetric CPC \\ Building Integrated Concentrating Photovoltaic \\ Building Integrated Concentrating Thermal \\ Building Integrated Solar Daylighting
}

Building Integrated Concentrating Photovoltaic/Thermal

Building Integrated Concentrating Photovoltaic/Daylighting

Building Integrated Concentrating Thermal/Daylighting

Building Integrated Concentrating Photovoltaic/Thermal/Daylighting

Cross Compound Parabolic Concentrator

Compound Parabolic Concentrator

Concentrating Photovoltaic

dielectric crossed compound parabolic concentrator

Low-concentration facade integrated photovoltaic systems

Life Cycle Assessment

Life Cycle Impact Assessment

Luminescent solar concentrator

Mirror Symmetrical Dielectric totally internally reflecting concentrator

Maximum Power Point Tracking

Monte Carlo ray-tracing method

Miniature Concentrating PV

Phase Conserving Method

Photovoltaic Facades of Reduced Costs Incorporating Devices with Optically Concentrating Elements

Reflective Adaptive Solar Façade

Square Elliptical Hyperboloid

Total Internal Reflection

Window Integrated Concentrated PV 


\section{Introduction}

It has been estimated by many institutions that the building sector energy consumption accounts for about $30 \%$ of the world's total energy demand which includes electrical power, heating, and cooling etc. Solar energy as a renewable energy has a huge potential for these applications, especially solar concentrating system which can provide a good choice for the solutions. The concentrating system can decrease the use of PV cells by using low-cost transparent material thus decrease the overall system cost and meanwhile increase the temperature of the heat source, therefore it is able to provide the function of heating, refrigeration, dehumidification and daylighting for buildings. In this regard, many researchers have focused on designing and introducing the use of the concentrating devices on buildings. However, for the integration with the building, the solar concentrator should be installed without any tracking components or seasonal adjustments (called stationary concentrator or static concentrator), and can also substitute some parts of the building structure thus further reduce the overall system cost [1], which is different from the traditional solar concentrator with tracking system, and has its own characteristics.

The first static concentrator, the compound parabolic concentrator (CPC), was studied in the late 1960s, but it was impractical due to its considerable concentrator height. Since then, several static concentrators have been devised over the past several years, mainly by means of reflective static concentrators [2]. Several papers have described static concentrators as being feasible for making a cheaper PV module than a 1-sun flat-plate module [3]. Numerous studies have been carried out in designing various stationary concentrators for different applications. The main reason for designing the low concentrated stationary system is to collect the irradiation by considering the daily and seasonal change in position of the Sun. This collection takes place without the need of Sun tracking like the high concentration systems [4]. Over the last few years, the number of solar concentrating systems have been significantly increased for the building integration as such systems are more efficient in use of space rather than the conventional flat modules [5].

This paper tried its best to search for the most useful articles including the older articles dating back to 1990s and state-of-the-art ones in recent years and make the classification by different functions. This was done to present a simple yet effective way for all people who are interested in this topic, i.e. researchers and government agents from all over the world to easily understand it. The previously published articles on the topic of low concentration solar energy utilization technologies mainly focused on the design or optimization of the concentrators, while this paper only looked into the ones that aimed for building applications to make a more specific review. In fact, whether the energy crisis happens or not, the development of the renewable energy technologies especially for buildings is a common goal of all countries, and there is no doubt that building integrated concentrating devices display a promising direction.

Therefore, the main goal of our paper is to present a concise review on the building integrated concentrating devices. In the main context, the demands, types and applications of the building integrated concentrating photovoltaic (BICPV), building integrated concentrating solar thermal (BICST) and building integrated concentrating solar daylighting (BICSD) are introduced individually. Furthermore, the above mentioned three kinds of solar energy utilization ways have been proved to be mature and advanced technologies. To use the solar energy more efficiently with the limited installation area of buildings, researchers have focused on combing two or three functions of BICPV, BICST and BICSD as BICPV/T, BICPV/D, BICST/D and BICPV/T/D. There are a lot of studies about this issue, the type and application of which are also reviewed in detail in this paper. This review deeply investigates the structure, working principle and the actual performance of these building integrated concentrating devices thus provides a detailed and accurate reference for readers.

\section{Building integrated concentrating photovoltaic (BICPV)}

\subsection{The demand for BICPV}

Great accomplishments in progress of solar cell material and their efficiency have been reached, but still outstanding problems are in existence in the commercialization of PV panels. The main reason for the existed problems is basically due to the failing in mass market and the overpriced solar cell materials. Two current applications for the use of solar cells for electric power production have been introduced to address existing constraints. The first is Building Integrated PV (BIPV), which is based on the potential availability of existing area which can be used for PV installations [6]; Facades and roof areas in buildings are targeted spaces for this application. The second is Concentrating Photovoltaic (CPV), which aims to decrease the cost of PV by using cheaper materials of concentrator instead of costly solar cell materials [7].

In addition to the above-mentioned benefits of BIPV systems, these systems have more priorities than conventional photovoltaic panels, as reported by Oliver and Jackson [8]:

a. In addition to the basic construction costs needed for photovoltaic panels, no area and land costs for system installation are required.

b. The electricity produced from BIPV systems is used on site and therefore there is no loss of energy due to the transition of electricity in conventional photovoltaic systems. This advantage of the BIPV system is beneficial for commercial buildings, as the demand and supply of peak power is equaled.

c. PV modules in the BIPV system decrease installation costs by replacing some costly important roof or facade components. In addition, as new components produce energy, the building becomes more energy efficient.

Since the fast growth of photovoltaic technology, the PV system has made continuous progress in both industrial and commercial sides. As a result, installation capacities of different types are being expanded worldwide. Modern buildings are usually built and finished in different ways with different materials, such as photovoltaic modules, which can be used as special finishing materials for both old and new buildings [9].

Roof tiles, asphalt shingles, and facade elements are some components which can be replaced by BIPV. Utilizing the BIPV systems can significantly reduce the thermal loads due to the direct sun radiation. The design of ventilated walls, facades and roofs plays a key role in performance of BIPV systems [1].To expand the application of the BIPV system, the price of electricity produced should be lower than that of other electricity supply sources. Concentration technology can further reduce the cost of BIPV by reducing the silicon surface while achieving the desired performance [10]. Generally speaking, concentrators are frequently 
used to concentrate solar radiation from a larger front opening to a smaller receiver to which photovoltaic modules are connected [11]. Compared to the same scale-PV cells, concentrators are much cheaper $[12,13]$. Initial cost of simple photovoltaic cell is high, and its electrical conversion efficiency is very low, usually only $6 \%$ to $15 \%$. To solve this problem, concentrator-photovoltaic systems (CPV) use cheap optical elements such as Fresnel lenses or mirrors with minimal reflection [14]. The concentrator increases the luminous flux on PV surface, so fewer PV materials are needed [14]. As predicted by Professor F.K.Mallick et al. [15], the low-concentration concentrator for the building application as the BICPV can attain a cost reduction of $40 \%$ over similar non-concentrating system.

\subsection{Types/Applications/Structures of BICPV}

Yoshioka et al. [16] have reported several refractive static concentrators with two-dimensional (2D) non-imaging lenses. $1.75 \times$ is the optical concentration ratio of the optimized 2D lens [17]. Three-dimensional (3D) lenses have also been designed to realize higher optical concentration. A new three-dimension (3D) lens with a higher $2.3 \times$ concentration ratio for a static concentrator is proposed by Yoshioka et al. [18]. The single concentrator model at normal impact and this ratio is kept constant up to a $60^{\circ}$ incidence angle. Also, the optical properties of a series-coupled concentrator model are examined to compare with the properties of a single concentrator model. At smaller incidence angles, due to the reflection from adjacent lenses, the ratio of optical concentrations is higher, while the ratio of optical concentrations is lower at higher incidence angles caused by the shielding effect. Since no surface monitoring and design mechanism is required, static concentrator modules can be used for PV buildings. The new 3D lens was designed on the basis of the previous 3D lens by the following procedure: the entry aperture is divided into $\mathrm{n}$ rectangles (shown as A1 $\pm \mathrm{An}$ in Fig. 1(b)). The marked areas of the bottom rectangle A1 are replaced by quarter circles, because L2 is longer than L1 (as shown in Fig. 1(b)). The radius is determined to be equal to L2; also, as for all of the rectangles except A1, the four corners are replaced with quarter circles of a radius proportional to that of A1; and presented in Fig. 1(c), new 3D lens are shaped by piling up all of the above-mentioned rounded rectangles. A minimum of $10 \%$ loss of incident energy is unavoidable due to the difference in refractive index b/w the PV cell and optic element. With regard to this new 3D lens, further improvement in the optical concentration ratio can be expected by devising a new design for almost $100 \%$ of the normal incident rays to reach the exit aperture.

\section{Fig. 1}

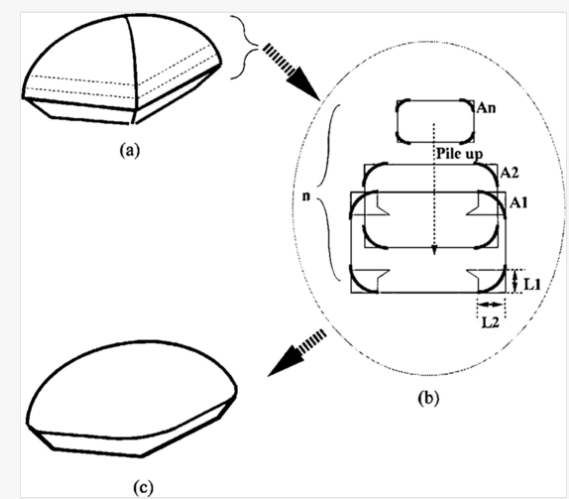

Design concept of a new three-dimensional (3D) lens for a static concentrator: (a) previous 3D lens; (b) cross-section; (c) new 3D lens [18].

Sarmah et al. [4] has introduced a low concentrating photovoltaic system with a newly designed concentrator. The concentrator is abbreviated as a complex parabolic hub with $6 \mathrm{~mm}$ of receiver width. In order to provide a stationary CPV system that can be properly performed at higher latitudes $\left(>55^{\circ}\right)$, project system parameters have been selected with respect to the seasonal change of the solar path. The CPV prototype system is built with 28 solar cells that are divided into two wires with 14 solar cells in each string. The solid CPV prototype system is designed for external specifications so it contains solar cells that are accurately closed with strong glass cover. The design of such a CPV is given in Fig. 2. The CPV module performance analysis is conducted and compared with a similar part that does not concentrate over three continuous days in different weather conditions. The results showed that the designed dielectric concentrator is superior in performance. In addition, the electrical output is correlated with the results of the indoor specifications [4]. With an appropriate size and a naturally integration, This design is suite for Building facades integration in northern latitudes $\left(>55^{\circ}\right)$.

Fig. 2

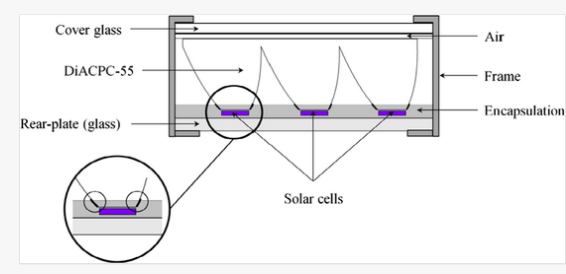

Schematic drawing of the prototype CPV system with dielectric concentrator comprising reflective films for optical losses reduction [4].

Aldegheri et al. [5] designed a building-integrated solar system for renewable electricity production or pre-heating of water, building lighting and partially shading. There is a design of a vault that can achieve the ability to withstand curvature loads and meanwhile create an optimum shape that always has parts 
facing up to sun in perpendicular direction. PVD silver coated Aluminum foil with high reflectance (reflection about 95\%) can be achieved. The optical concentration is achieved by the mirror-like foil which is located in the parabolic trough. The photovoltaic form of Solar F-light module is given in Fig. 3.

\section{Fig. 3}

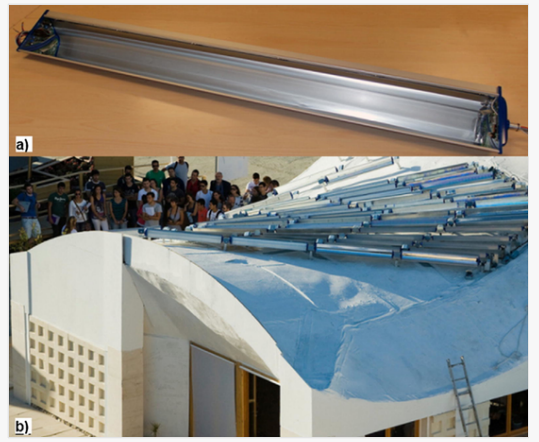

(a) The PV version of the Solar F-Light concentrator and (b) an image of the house roof showing the arrangements of the solar modules [5].

In the Astonyshine project, a series of 46 F-lights on roof of a home on 12 straight lines with a peak power of 1010 Watts can cover part of the energy needs of the villa. Concentrators are specially located at ten lines of four modules and two lines of three modules. In each line, the modules are in series connection to make six strings, five strings each with eight modules each and one string with six modules. Each line is further linked to a Steca Solar SG500M type inverter, that provides max power point tracking (MPPT) [5].

Muhammad-Sukki et al. [19] introduced a new type of mirror symmetrical dielectric totally internally reflecting concentrator (MSDTIRC) that offers significant optical gain and consequently increases the electric energy of solar photovoltaic system. Mirror symmetrical dielectric totally concentrator (MSDTC) can decrease the price of a photovoltaic system and also be a substitute solution to the BIPV system. Geometrical properties and design steps of MSDTIRC are presented in. Dielectric totally internally reflecting concentrator (DTIRC) used by the MSDTIRC, based on the PCM (phase converting method). Fig. 4 shows the steps for manufacturing the MSDTIRC, starting with position (plane) 1. MATLAB is employed to produce coordinates (point clouds) of MSDTIRC and then transmitted to the software AutoCAD or GeoMagic to produce the CAD model that provides a standard ACIS text file as shown in Fig. 4. A comparison was made on the basis of unit area of photovoltaic material in each PV panel between the MASTER panel and the traditional photovoltaic lighthouse to estimate panel performance.

\section{Fig. 4}
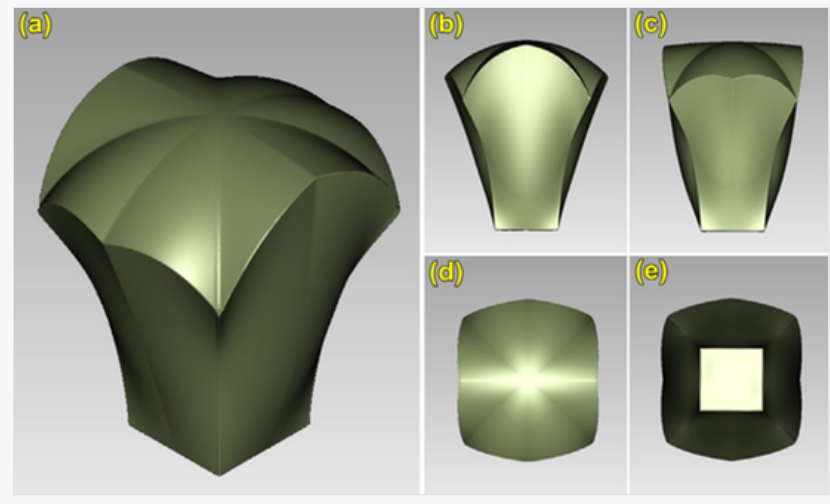

MSDTIRC, where (a) is the isometric view; (b) is the side view 1; (c) is the side view 2; (d) is the aerial view, and (e) is the bottom view of the concentrator [19].

Baig et al. [20] designed an integrated concentrated PV system for buildings. It consists essentially of the concentrating element, the encapsulating material and the PV cell located between 2 glass panels as displayed in Fig. 5. System dimensions are shown in Fig. 6. Such concentrating devices can be simply obtained from pure polyurethane material by means of simple stainless-steel molds. Encapsulation material is used to fix solar cells with concentrating devices. A sample of several concentrator elements was made of polyurethane [20]. Si elastomer that have same refractive index (1.5) is employed to capture the cell to attain the best optic connection. This can be in array form. Space among specific units can be modified to meet daylighting needs. 


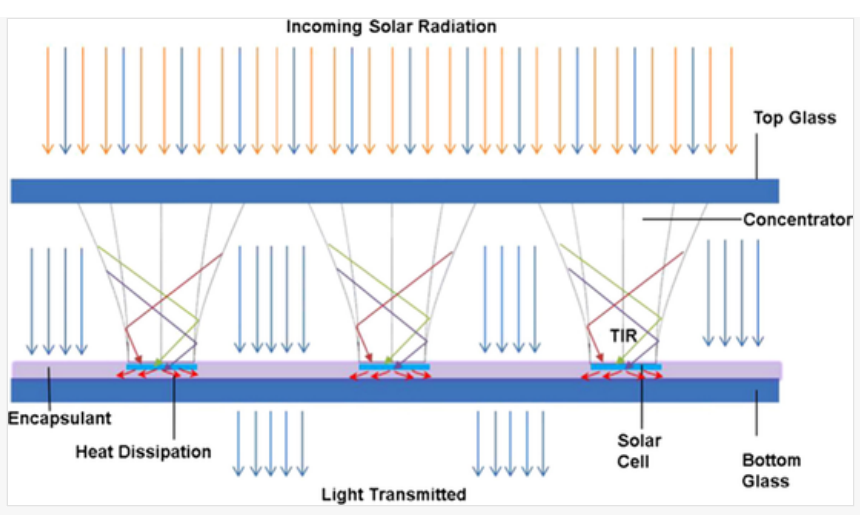

Total internal reflection (TIR) of light rays to the solar cell [20].

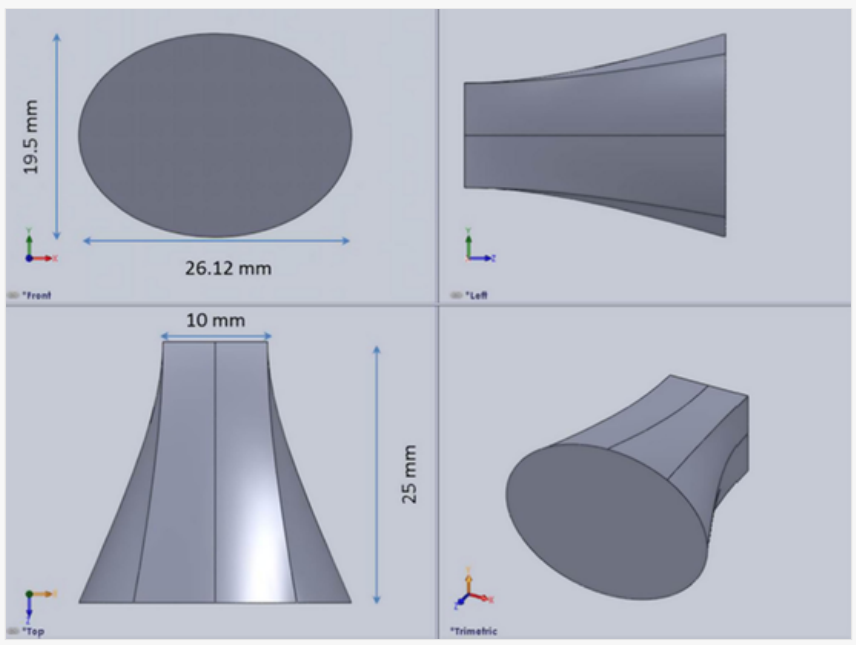

Dimensions of the square elliptical hyperboloid concentrator [20].

Sarmah et al. [21] designed, manufactured and analyzed dielectric asymmetric CPC (ACPC) that is suitable for the application of BICPV with two different CPV modules. The fully-built CPV and non-concentration module for internal characterization is displayed in Fig. 7a and 7b. Two CPVs of different alignments titled CPV-1, CPV-2 as displayed in Fig. 8(a) and (b), are used for CPV module performance analysis. By initial experimental analysis, CPV module through dielectric concentrator built by conventional method (CPV-1) show more optic losses. At the border between the concentrator and the encapsulation (both sides of cell), light comes out of the area where concentrator is in contact with the encapsulant (Fig. 8(a)). The modified module is made by a thin reflective film that covers the height of $2 \mathrm{~mm}$ concentrator near the receiver area and the optically attached cover glass to diminish losses of the dielectric interface to reduce optical losses (Fig. 8(b)). The low concentrating system can replace the traditional BIPV at higher latitudes. Experimental results indicate that the power generated by the CPV is $£ 0.16 / \mathrm{W}_{\mathrm{p}}$, which is cheaper than that produced by the PV module [21]. 


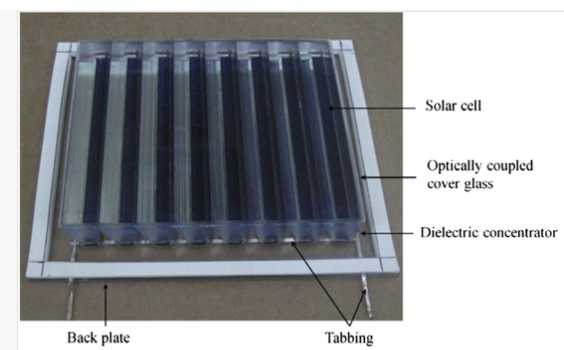

(a)

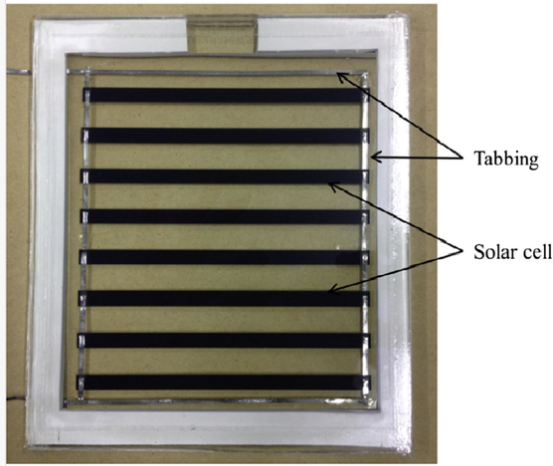

(b)

(a) Image of the CPV module constructed for indoor characterization with solar simulator; (b) Image of the glass-glass laminated non-concentrating PV module constructed for indoor characterization [21].

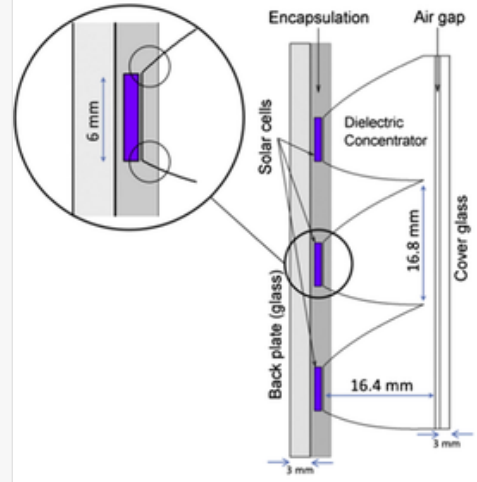

(a)

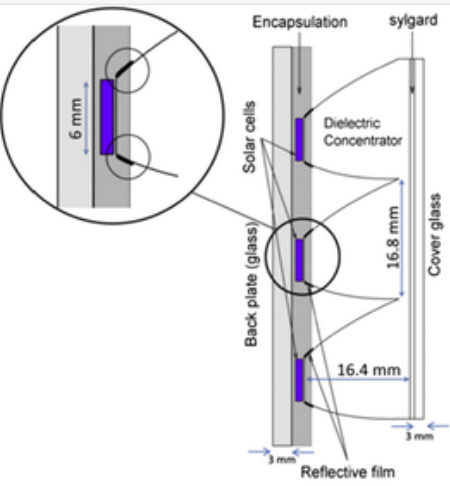

(b)

(a) Schematic diagram of the standard dielectric concentrating PV system (CPV-1); (b) Improved concentrating PV system with reflective films to reduce optical losses (CPV-2) [21].

Fernández et al. [22] has developed a model that is based on the artificial neural network to evaluate the performance of an low concentration photovoltaic (LCPV) for building integration with an appropriate margin of error. Main parameters such as: direct venting, diffuse ventilation, temperature, and longitudinal and transverse inclinations have been taken into account in the model. It offers the benefits of estimating the maximum output of BICPV, because there is no model in existing works for assessing the maximum output of the LCPV for building integration in outdoors. This developed model can be used as a tool for predicting energy production in the LCPV and so, this model can support the promotion of its application.

The reflective 3D crossed compound parabolic concentrating photovoltaic system (3D CCPC PV) was made by Mammo et al. [23]. Its optical and electrical performance was examined for the construction of combined photovoltaic applications. The module is a prototype created on the reflective $3 \mathrm{D}$ CCPC of aluminum. CCPC contains 81 single 3D CCPC positioned in a $9 \times 9$ matrix as displayed in Fig. 9. Each 3D CCPC is made to have an input and output ports of $19 \mathrm{~mm}$ and $10 \mathrm{~mm}$, respectively, with $16.16 \mathrm{~mm}$ truncated height, attaining a $3.61 \times$ concentration ratio with a half acceptance angle of $30^{\circ}$. The maximum power ratio produced by the $3 \mathrm{D} \mathrm{CCPC}$ photovoltaic to that of a similar non-concentrating type gives a $3 \times$ concentration ratio with $14 \%$ maximum electrical conversion efficiency. The main concern that the BIPV designer should take into account is the acceptance range and its compactness, so that the integrity of the construction and the collection of solar energy become optimal. The developed CCPC, which is static and shortened, has reached a $60^{\circ}$ absorption angle with high efficiency. With pleasing architectural design and appropriate size, the results indicate that 3D CCPC photovoltaic can be a substitute to low-concentrate PV for facade integration into the building [23]. 


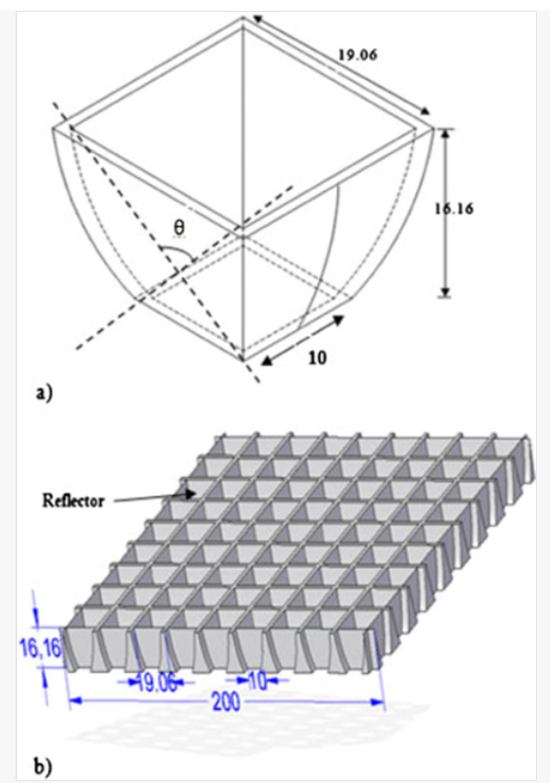

The schematic diagram of (a) a unit 3D crossed compound parabolic concentrator profile and (b) $9 \times 93 \mathrm{D}$ crossed compound parabolic concentrator (dimensions in mm). The angle $\theta$ indicates the acceptance angle of the compound parabolic concentrator [23].

The concentrator introduced by Sellami et al. [7] can be naturally used in the window integrated concentrated photovoltaic (WICPV), which is static, compact and also capable of collecting maximum energy. The window offers natural daytime lighting transmission function as well as the generation of renewable electricity. The concentrator is adjusted for various angles of incident light beams. Testing the top combination of efficiency and angle of absorption, $4 \times$ dielectric-based concentrator, works with complete internal reflections. It has been determined to have $40 \%$ constant efficiency for angle of acceptance equals to $120^{\circ}\left(-60^{\circ}\right.$ and $\left.+60^{\circ}\right)$ and the optical concentrating ratio (OCR) of $1.6 \times$, which confirms the collection of energy from both diffused and direct radiation during the whole day. Greater OCRs are attained for various sizes of concentrator; though, the angles of acceptance are comparatively low.

Sellami et al. [24] also suggested a new idea for double glazed WICPV. Three different geometric properties for the development of a new concentrator design for WICPV were considered in their work. These are (a) elliptical aperture for inlet; (b) section of hyperbolic profile; (c) square aperture for outlet. Due to the growing demand for stationary concentrators for the construction of the integrated photovoltaic system, this design emphases on the use of a fixed concentrator. Due to its compact structure, this new 3D CPV geometry for stationary concentrator apply to transparent facades and roofs or windows of building. This new 3D CPV geometry for stationary concentrator will be compact enough to incorporate into BIPV and particularly for facades, windows or roofs. To decrease the production costs of reflective surface coatings, the 3D Square Elliptical Hyperboloid (SEH) concentrating system being investigated are made by transparent dielectric. This also maintains the window transparency where concentrating system will be installed. Also, the concentration of light will be done by the total internal reflection. Dependency of optical efficiency on different SEH dimensional parameters compared to the different angles of incoming light beams has been studied. Criterion for selecting the improved SEH profile was to achieve the balance between highest efficiency, compactness and widest acceptance range [24]. The results motivate the usage of stationary SEH, making it good for usage in roof or transparent facade in the buildings. It is compact, and provide natural lighting in building space and it does not need a tracking mechanism, which decreases the cost of this system, matches the demand of architectural design, and makes it an affordable source of solar energy [24].

A study was conducted by Oliver and Jackson [8] on a novel 3D static concentrator that is coined with the SEH to be used on glass windows or facades to produce the renewable electricity. The main motive of this research is to make a compact and static concentrator, which will simultaneously be able to collect the maximum energy. This study was conducted to make a low concentration system for BIPV. The major use of new proposed concentrators is transparent building facades. The considered concentrating system in this paper allows the design of a stationary concentrator without any requirement for tracking which is classified as non-imaging concentrators. The suggested 3D structure is dependent on 3 major geometric parameters, including elliptical inlet aperture geometry, square output aperture and hyperbolic profile. SEH, as a 3D system, gives a flexible solution to the architects. This is a feature of a wide acceptance angle. In addition, $\mathrm{SEH}$ is a viable solution for CPVs in remote areas in comparison to CPVs with tracking systems. Periodic maintenance for the CPV is expensive and maybe not practical in some cases [8].

Bowden et al. [3] introduced an advanced three-dimensional method for static concentrators, offering increased concentration ratios with thin designs as compared to previous two-dimensional static concentrator PV modules. This design attains a $3.6 \times$ concentration ratio while capturing $90 \%$ of annual radiation without a tracking system. Employing the new idea for the light trapping which can be applied to any roof tile shape, the static concentrator can be used. However, in this research, the concentrator design having a flat top is employed. They used a tile design with flat top surface to get their research purpose, and the authors indicated that the static concentrator design can be applied in different shapes of the roof [3]. Fig. 10(a) illustrates one of the least complex and common static concentrators. Fig. 10(b) shows the structure of the system while high concentrations and intercept factor are produced, which is not practical in real terms as the PV cell is placed vertically. Also, system structures are comparatively large for PV cell dimensions. The vertical installation of cells makes the module complex and also specifies that the cell should be thin. Also, the enormous amount of material on both sides of the cell makes it challenging to transfer the heat. Fig. 11 shows horizontally positioned solar cells having concentration of $3.8 \times$ and they have an intercept factor of 0.95 . The horizontal installation of cells enables the system to be more identical to traditional flat plates, thus facilitating easier production. Analysis and comparison of electrical outputs suggests 
that an innovative three-dimensional design has better performance than the conventional flat panel module. Heat conductivity of materials used plays a major role in system performance, which must meet the thermal and optical requirements of the system. The best three-dimensional design performance was recorded considering loss in diffused light and slightly high temperature of cell.

\section{Fig. 10}

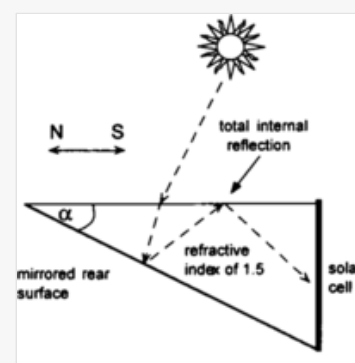

(a)

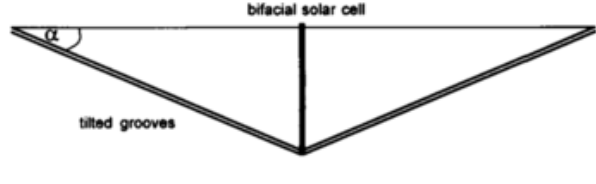

(b)

(a) Cross-section of a simple two-dimensional static concentrator; (b) cross-section of a three-dimensional concentrator with a bifacial solar cell and tilted grooves on the rear surface [3]

\section{Fig. 11}

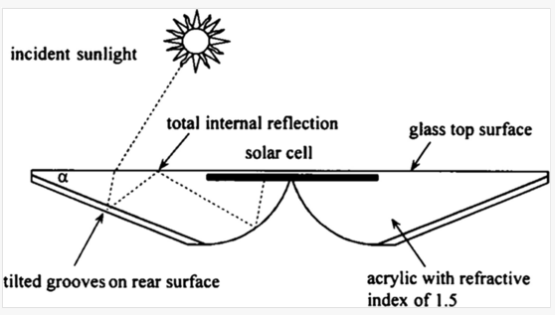

Cross-section of the concentrator. The tilted grooves on the rear surface of the module run along the back surface of the module from the curved section to the edge of the module [3].

The prototype of first generation of Photovoltaic Facades of Reduced Costs Incorporating Devices with Optically Concentrating Elements (PRIDE) that comprises monocrystalline silicon solar cells of 3 and $9 \mathrm{~mm}$ wide, displayed remarkable output power in comparison to the similar non-concentrating system under the indoor Sun simulator conditions. For mass production, the second-generation PRIDE is made to incorporate 6 mm wide "Saturn" solar cells into a dielectric concentrator absorber [15]. The arbitrarily chosen concentrator was characterized in outdoor from 24 (E3kWp) second generation PRIDE type concentrating systems. Initial concentrators attained an optical concentrating ratio of 2.01 in comparison to a non-concentrated system. The conversion efficiency from solar to electric energy was $10.2 \%$ in the outdoor experimental test. For mass production, a $40 \%$ reduction in costs could be achieved through the use of this technology. For this design shown in Fig. 12, the concentrating ratio of the un-truncated system (aperture / receiver area) is $4.46 \times$. $81 \%$ of the truncated system with $2.45 \times$ concentration ratio has a high efficiency at various incidence angles.

\section{Fig. 12}

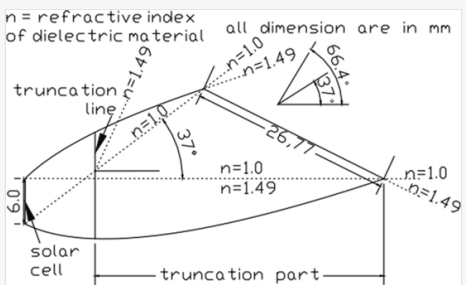

An asymmetric CPC consisting of two different parabolas of acceptance angle $0^{\circ}$ and $37^{\circ}$. The angular acceptance of the system is indicated on the figure for both the nondielectric mirror system ( $\left.\mathrm{n}^{1 / 4} 1\right)$ and the dielectric system with a refractive index of 1.49 [15].

A non-imaging solar concentrating PV system was designed, assembled and characterized by Mallick et al. [25] at Ulster University at Northern Ireland. Various PV strings in series connection were characterized under external environment, and non-concentrated panel is used for comparison. The power generated by the system is 1.62 times the power produced by flat PV. To decrease the amount of reflector material, system weight and price, the solar concentrator is truncated by $54 \%$, resulting in a geometric ratio of $2.01 \times$. The theoretical power gain is $2.0 \times$, which is $18 \%$ more than the experimental value, which is due to series resistance in PV cell wires. While power value is increased to a factor 1.62, the temperature of the aluminum backplate of solar concentrator is only 12 degrees greater than the flat system. Almost $8.5 \%$ of the electric efficiency was attained by a flat panel in comparison to $6.8 \%$ for this system having a fill factor (defined as the ratio of the maximum power from the solar cell to the product of open-circuit voltage $\mathrm{V}_{\mathrm{oc}}$ and short-circuit current $\mathrm{I}_{\mathrm{sc}}$ ) of $65 \%$. The solar concentrating 
PV system was experimentally evaluated in comparison to the similar non-concentrating system. Systems with different number of photovoltaic strings were interconnected and a $62 \%$ increase in power achieved in comparison to the similar non-concentrated system with same total radiation capture for unit area. Solar to electrical efficiency is calculated which is $8.6 \%$ and $6.8 \%$ for the non-concentrated plates and concentrating systems respectively. Temperature calculated in the concentrated system was $12^{\circ}$ greater than the non-concentrated system [26]. The experimentally characterized system is shown in Fig. 13.

\section{Fig.13}

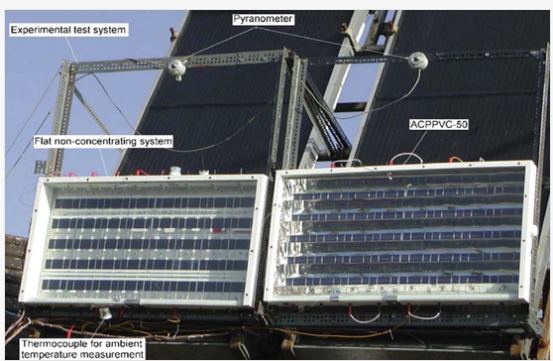

Non-concentrating and asymmetric compound parabolic photovoltaic concentrators under outdoor experimental characterisation at the Centre for Sustainable Technologies, University of Ulster. Both systems are identical with equal numbers of PV cells connected in series in each system [26].

Built-in low concentrating facade integrated Photovoltaic systems (LFP) made of acrylic CPC segments that have their solar cell absorbers can play a vital role in decreasing the cooling load in the building. Sabry et al. [27] analyze the effect of truncation on optical performance of CPC. Truncated CPCs were done with 8 different percentages as compared to the full CPC, and effectiveness of the truncated CPCs is simulated by commercial simulation software. Optical efficiency was calculated at different angles of incidence and concentration ratios were also calculated at these angles. The LFP system consists of linear CPC segments that extend in horizontal direction across windows. Numerous of these CPC segments are set in vertical direction, depending upon the dimensions of the window pane and their axis makes the angle equal to the latitude of the suggested location $\left(30^{\circ}\right)$ with horizon. Their study found that reducing the upper side of $\mathrm{CPC}$ segment is a trade-off between the production of electricity and radiation conveyed in the window. It was found that all CPC segments are more effective for greater incident angles.

A new lens-walled CPC was studied and simulated by Su et al. [28], which has thin lens connected to the interior of common CPC or it has lens that has to be mirror-coated on its outer surface. Lens shape is created by rotation of parabola curves of the CPC internally with minor degree by upper endpoints of curve. Refractive lenses allow the CPC in concentrating light from a wider angle of incidence. Optical examination software PHOTOPIA serves to test the principle of this CPC with the lens and investigate its performance in relation to a common CPC. Parabola curves of the traditional CPC are rotated inward at a certain degree about their top end points to become a new CPC, and then the dielectric material is filled between original and new curves of CPC to create a lens [29]. The outer lens surface has reflecting coating, or a lens is connected to the interior of simple CPC to create a lens-walled type CPC. The lens can turn the light that comes with a greater angle of incidence in the direction within acceptance angle of CPC, as shown in Fig. 14. This CPC has the actual half acceptance angle greater than its nominal half acceptance angle. The proposed CPC structure can ideally lead the less weight than a solid dielectric CPC [30]. This superiority is due to the higher half-angle of acceptance than that of conventional mirror CPC [31].

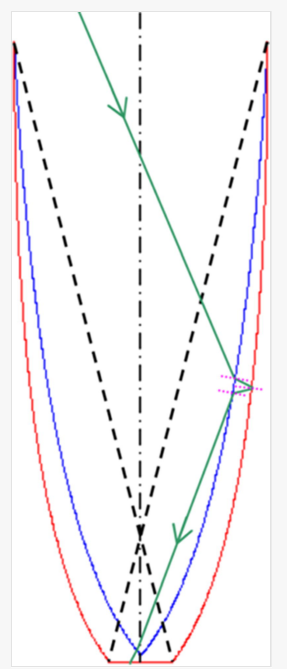


There is an experimental and simulation research on flux distribution of lens walled CPC as compared with mirror CPC carried out by Li et al. [32]. The lenswalled CPC was suggested due to its greater half acceptance angle. It has relatively more even flux distribution as compared to mirror CPC with the same concentrating ratio. The lens walled CPC was manufactured and assessed relative to mirror CPC, which was intended to assess the flux distribution. Their results conclude that the fill factor of mirror CPC gets dropped more rapidly as compared to lens walled CPC. This shows that lens walled CPC has more even distribution of fluxes $[33,34]$.

The roof or wall building can be integrated with a lens-walled CPC PV. The integration must take a lot of factors into consideration such as some architectural standards and safety concerns. The building structure, latitude, longitude, cost of installation is some of the necessary factors. Since total internal reflection is a more effective way to collect solar radiation, which further increases the performance of lens-walled CPC, Li et al. [34] suggested a lens-walled CPC having air gap that sets an air between the lens-walled structure and the mirror CPC. Due to this, the incoming solar radiation can be traced through the total internal reflection, and those that cannot meet the demand for complete internal reflections can be collected by the specular reflection. Experimental and simulation analysis showed an increase of about $10 \%$ for optical performance compared to the original lens walled CPC.

Traditional symmetric concentrators are more appropriate for integration on the roof of the building, and the asymmetric concentrator is more appropriate for integration on the facade of the building [25]. Xuan et al. [35] developed an asymmetric lens-walled CPC for application on building south wall. Through the optical and experimental evaluation, it has been found that the acceptance angle range of the asymmetric lens-walled CPC can be up to $60^{\circ}$ with high efficiency, making it suitable for using on the southern wall of the building [36]. An asymmetric lens walled CPC is also capable of providing a relatively even distribution on the photovoltaic cell, which could expand the Photovoltaic output [37] Considered the base height and rotation angle for appropriate size and pleasing architectural design, this asymmetric lens-walled CPC as a static concentrator would be a good solution for the building south wall integration.

Another type of low concentration concentrator used for the BIPV application is the luminescent solar concentrator (LSC). The LSC is a radiation concentration device for the production of electricity power. Luminescent solar concentrators work on a large-area radiation collection principle, transformed by luminescence (specifically fluorescence) and directs the generated radiation to a relatively small output target [34]. Typical LSC, in its simplified form, consists of a polymer or glass plate that acts as luminophores either dispersed or on a coated surface [34,35].

Active controlled building facade systems offer a promising energy management and comfort system as well as on-site power production, such as Adaptive Solar Facade (ASF), which uses thin solar photovoltaic technology combined with dynamic dual-axis shading \& daylighting control on the facades [38]. Powell et al. [39] suggested a reflective adaptive solar facade (RASF) that includes concepts of energy management and comfort in the building through shading, redirecting sunlight through reflecting panels and power generation. By the use of a concentrating PV receiver, it can compensate for the cooling load of the building's southern wall and also provide electricity. Total net energy savings are between 2 and $2.5 \mathrm{kWh} / \mathrm{h}$ in months of March and December as compared with those without RASF.

The Life Cycle Assessment Study (LCA) of Building Integrated CPV (BICPV) was conducted at University of Lleida by Menoufi et al. [40]. The assumptions for presenting the actual building are taken into account and comparison is made with the hypothetical conventional scheme of BIPV systems. The LCA is conducted using the EI99 approach. Differences in the percentage of contribution of component influence between approaches EI99 and EPS 2000 were observed. However, both methods coincide with the conclusion of positive impact by replacing of BIPV schemes with BICPV. The integrated concentrators consist of 22 flat coated reflectors $(2 \times 0.16 \times 0.006 \mathrm{~m})$, with a max $10 \times$ (suns) concentrating ratio. Its installation is shown in Fig. 15. The results of the LCA using EI99 method are shown in Fig. 20, which is the reference used in this study. A comparison of the effects of BICPV and BIPV (left on Fig. 16) \& related CPV and PV (right on Fig. 16) is presented. The results indicate that installing BIPV rather than BICPV shows an increase of $13.5 \%$ of environment impact.

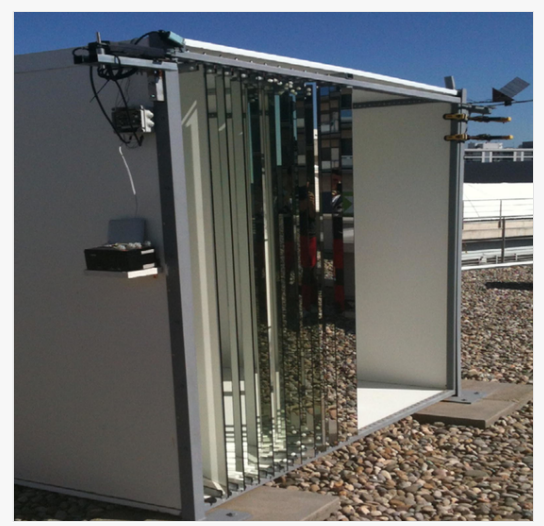

The reflectors facade: during the installation of the concentrating PV façade at the Applied Energy Research Centre (CREA) at the University of Lleida (Spain). The tracking system is noticed on the left [40]. 


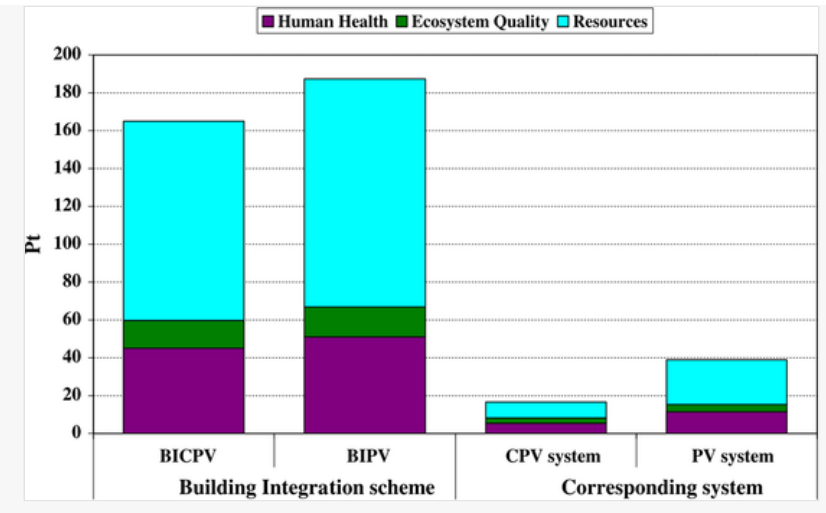

Comparison between the BICPV and BIPV schemes on the left, and the corresponding CPV and PV schemes on the right, using the EI99 methodology [40].

The comparison of different BICPV concentrators is given in Table 1.

\section{Table 1}

(i) The presentation of Tables and the formatting of text in the online proof do not match the final output, though the data is the same. To preview the actual presentation view the Proof.

The comparison of different BICPV concentrators.

\begin{tabular}{|c|c|c|c|c|c|c|}
\hline Authors/Country & Concentrator type & $\begin{array}{l}\text { Concentrator } \\
\text { structure }\end{array}$ & $\begin{array}{l}\text { Geometric } \\
\text { concentration } \\
\text { ratio }\end{array}$ & Acceptance range & $\begin{array}{l}\text { Optical } \\
\text { efficiency }\end{array}$ & Comments/Application \\
\hline $\begin{array}{l}\text { Yoshioka et al. } \\
{[17] / \text { Japan }}\end{array}$ & Lens-type $2 \mathrm{D}$ concentrator & & $\begin{array}{l}\text { Is the function } \\
\text { of the half } \\
\text { acceptance } \\
\text { range }\end{array}$ & $\begin{array}{l}\text { half acceptance angle of } \\
20^{\circ}, 25^{\circ}, 30^{\circ} \text { and } 35^{\circ} \text { are } \\
\text { studied }\end{array}$ & Over $90 \%$ & $\begin{array}{l}\text { The structure of the concentrator is easy to get. But, it's } \\
\text { found that the best half acceptance at } 25^{\circ} \text {, so it's better } \\
\text { to installed on the building roof with the inclination } \\
\text { angle near the local latitude }\end{array}$ \\
\hline $\begin{array}{l}\text { Yoshioka et al. } \\
{[18] / \text { Japan }}\end{array}$ & Lens-type 3D concentrator & & $2.69 x$ & $60^{\circ}$ & $\begin{array}{l}\text { Maximum } \\
\text { value of } \\
85.5 \% \text { and a } \\
\text { constant } \\
\text { value of } \\
74.3 \%\end{array}$ & $\begin{array}{l}\text { The structure of the 3D concentrator is complex which } \\
\text { would make it expensive. The concentrator has a wider } \\
\text { acceptance range with high optical efficiency. It's } \\
\text { suitable to be used on the building roof and with the } \\
\text { proper arrangement to avoid the shadowing effect, it } \\
\text { can also be used on building façade }\end{array}$ \\
\hline $\begin{array}{l}\text { Aldegheri et al. } \\
\text { [5]/Italy }\end{array}$ & parabolic linear trough & & $20 \times$ & $\pm 0.5^{\circ}$ & $90 \%$ & $\begin{array}{l}\text { The traditional parabolic linear trough, which is cheap } \\
\text { and easy to manufacture. The geometric concentration } \\
\text { ratio is } 20 \times \text { with high optical efficiency that enables } \\
\text { higher output of cell. However, for the actual } \\
\text { engineering, the tracking mechanism is required. }\end{array}$ \\
\hline $\begin{array}{l}\text { Muhammad- } \\
\text { Sukki et al. [19] } \\
\text { /UK }\end{array}$ & $\begin{array}{l}\text { Mirror symmetrical } \\
\text { dielectric totally internally } \\
\text { reflecting concentrator }\end{array}$ & & - & $\begin{array}{l}\text { Between } \pm 15^{\circ} \\
\text { and } \pm 20^{\circ} \\
\text { Between } \pm 20^{\circ} \text { and } \pm 30^{\circ} \\
\text { Between } \pm 30^{\circ} \\
\text { and } \pm 40^{\circ} \text {; }\end{array}$ & $\begin{array}{l}\text { Maximum } \\
\text { optical } \\
\text { concentration } \\
\text { of } 13.54 \times\end{array}$ & $\begin{array}{l}\text { The structure is complex which makes it difficult to } \\
\text { manufacture. But within the normal height of the } \\
\text { standard PV module, the concentrator can achieve a } \\
\text { highest optical concentration ratio of } 13.54 \times \text { with an } \\
\text { acceptance range of } 15-40^{\circ} \text {, and it's suitable to } \\
\text { construct a same CPV module as the flat PV module } \\
\text { for the installation on the building roof }\end{array}$ \\
\hline $\begin{array}{l}\text { Baig et al. [20] } \\
\text { /UK }\end{array}$ & $\begin{array}{l}\text { dielectric based Symmetric } \\
\text { Elliptical Hyperboloid } \\
\text { (SEH) concentrator }\end{array}$ & & $6 x$ & $30^{\circ}$ & Around 54\% & $\begin{array}{l}\text { The concentrator is easy to manufacture for a wider } \\
\text { scope of application. However, optical concentration } \\
\text { ratio is below } 3.5 \times \text { with the geometric ratio of } 6 \times \text {. The } \\
\text { concentrator is recommended to be used on building } \\
\text { roof }\end{array}$ \\
\hline $\begin{array}{l}\text { Mammo et al. } \\
{[23] / \text { UK }}\end{array}$ & $\begin{array}{l}\text { 3D crossed compound } \\
\text { parabolic concentrator }\end{array}$ & & $3.61 \times$ & $30^{\circ}$ & $\begin{array}{l}75 \% \text { from the } \\
\text { experiment } \\
\text { and } 94.6 \% \\
\text { from } \\
\text { simulation }\end{array}$ & $\begin{array}{l}\text { The structure of the concentrator is a little complex and } \\
\text { the coating on the surface would make it more } \\
\text { expensive. The theoretical optical efficiency is very } \\
\text { high. It's suitable be used on the building roof }\end{array}$ \\
\hline $\begin{array}{l}\text { Chemisana et al. } \\
{[62] / \text { Spain }}\end{array}$ & Fresnel concentrator & & Above $5 x$ & $\begin{array}{l}\text { The tracking mechanism } \\
\text { is required }\end{array}$ & $50 \%$ to $96 \%$ & $\begin{array}{l}\text { The receiver remains stationary and the tracking is } \\
\text { performed by rotation of mirrors. Therefore, movement } \\
\text { is reduced enabling integration into buildings and }\end{array}$ \\
\hline
\end{tabular}




\begin{tabular}{|c|c|c|c|c|c|c|}
\hline & & & & & & $\begin{array}{l}\text { present possibilities for different requirements of } \\
\text { installations. It's designed for building façade }\end{array}$ \\
\hline $\begin{array}{l}\text { Bowden et al. [3] } \\
\text { /Austrilia }\end{array}$ & $\begin{array}{l}\text { Titled groves on rear } \\
\text { surface with the acrylic } \\
\text { filled inside }\end{array}$ & $\sqrt{2+1}$ & $3.8 x$ & - & Up to $95 \%$ & $\begin{array}{l}\text { The horizontal installation of PV cell makes the } \\
\text { module like a traditional module and thus, the } \\
\text { fabrication is easier. It's for photovoltaic roof tiles }\end{array}$ \\
\hline $\begin{array}{l}\text { Mallick et al. [25] } \\
\text { /UK }\end{array}$ & $\begin{array}{l}\text { Asymmetric mirror } \\
\text { compound parabolic } \\
\text { concentrator }\end{array}$ & & $2 x$ & $50^{\circ}$ & Up to $81 \%$ & $\begin{array}{l}\text { The asymmetric structure consists of two different } \\
\text { compound parabolic curves. The concentrator is } \\
\text { suitable for the static installation on the building } \\
\text { façade at the higher latitude areas }\end{array}$ \\
\hline $\begin{array}{l}\text { Mallick et al. [15] } \\
\text { /UK }\end{array}$ & $\begin{array}{l}\text { Asymmetric dielectric } \\
\text { compound parabolic } \\
\text { concentrator }\end{array}$ & & $2.45 \times$ & $66^{\circ}$ & Up to $82 \%$ & $\begin{array}{l}\text { The concentrator is filled with the dielectric material of } \\
\text { PMMA to collect the radiation through the total } \\
\text { internal reflection. The concentrator is suitable for the } \\
\text { static installation on the building façade at the higher } \\
\text { latitude areas }\end{array}$ \\
\hline $\begin{array}{l}\text { Sabry et al. [27] } \\
\text { /Saudi Arabia }\end{array}$ & $\begin{array}{l}\text { Compound parabolic } \\
\text { concentrator }(\mathrm{CPC})\end{array}$ & & $2.45 \times$ & $\pm 20^{\circ}$ & $\begin{array}{l}96 \% \text { for the } \\
\text { normal } \\
\text { incidence } \\
\left(0^{\circ}\right) \text {, while it } \\
\text { is } 74 \% \text { at } \\
\text { angle of } \\
\text { incidence } \\
\text { of } \pm 20^{\circ}\end{array}$ & $\begin{array}{l}\text { The traditional concentrator and it's easy to get, so the } \\
\text { cost of the CPC is very cheap. The symmetric CPC is } \\
\text { suitable for building roof application while the CPC } \\
\text { truncated in the asymmetric structure is suitable for the } \\
\text { building façade }\end{array}$ \\
\hline Su et al. [28]/UK & $\begin{array}{l}\text { Lens-walled compound } \\
\text { parabolic concentrator } \\
(\mathrm{CPC})\end{array}$ & & $2.4 x$ & $\pm 23.5^{\circ}$ & Up to $85 \%$ & $\begin{array}{l}\text { The lens-walled CPC is the optimization structure from } \\
\text { the conventional CPC. The formation purpose of this } \\
\text { structure is to use the refraction phenomenon to } \\
\text { enlarge the acceptance range of concentrator and to } \\
\text { decrease the use of material leading to reduction of } \\
\text { system cost and weight thus make it more suitable for } \\
\text { the building application }\end{array}$ \\
\hline $\begin{array}{l}\text { Riverola et al. } \\
{[97] / \text { Spain }}\end{array}$ & $\begin{array}{l}\text { Composed by a cylindrical } \\
\text { case and an inner cavity } \\
\text { filled with the circulating } \\
\text { dielectric liquid in which } \\
\text { the cells are immersed }\end{array}$ & & $10 x$ & $\pm 1.07^{\circ}$ & $81 \%$ & $\begin{array}{l}\text { Module tracks sun altitude angle change simply by } \\
\text { rotation, that can be done by single motor. Therefore, it } \\
\text { enables integration in building. Coefficient of non- } \\
\text { uniformity of } 0.13 \text { can be achieved }\end{array}$ \\
\hline Corrado et al. [98] & $\begin{array}{l}\text { luminescent solar } \\
\text { concentrator }\end{array}$ & & $1.2 x$ & - & $35.6 \%$ & $\begin{array}{l}\text { Although the optical efficiency \& concentrating ratio } \\
\text { of the LSC is very low compared with other kinds of } \\
\text { concentrators, LSC enables the development of } \\
\text { semitransparent glazing elements which can convert } \\
\text { building windows \& facades to electric generators }\end{array}$ \\
\hline
\end{tabular}

\section{Building integrated concentrating solar thermal (BICST)}

\subsection{The demand for BICST}

Solar thermal collector systems have been produced commercially since 19th century [41]. Some thermal collector is a heat extraction device which converts the incoming solar irradiations into heat energy. This thermal energy is then transferred through transport medium or working fluid for domestic use. The working fluids used for conveying heat are water, air or refrigerants. In general, these systems are used for air conditioning/air heating in buildings and for drying of different agricultural products, etc. [42].

In addition to technical and structural efficiency, the architectural integration of thermal collectors is also important i.e. they must be easy for architectural integration. The criteria for architecture of building integrated thermal systems set by IEA Task 41 are as follows [43]:

- Naturally integrated.

- Pleasing architectural design.

- Appropriate selection of materials and colors.

- Appropriate size

- Consistent in the building context

- Innovative design

However, the traditional flat solar thermal system can only supply the heat resource with low temperature, which restricts its application. In this case, the concentrating solar thermal systems can be a solution to this problem. One of main advantages of the concentrating technology is that it can provide the heat 
resource with higher temperature [44], thus it's more suitable for the building application. Building integrated thermal collector systems are either integrated with the roof of the building or with the façade of the building. Based on the collector type and size, they may be used in a way that makes them invisible and aesthetically attractive [10].

\subsection{Types/ Applications/Structures of BICST}

Harmim et al. [45] designed a non-tracking box-type solar thermal cooker that is equipped with CPC. They introduced the design and fabrication process of the prototype in detail and also conducted outdoor experiments to evaluate its actual performance. This prototype is fabricated with the materials that are locally available and by rustic means. It has a fixed type of asymmetric CPC that is used as booster-reflector and the absorber is in step form. The performance of this solar cooker was measured and also compared with other cookers. It was found that despite the season, the solar cooker was able to provide high temperatures with a stationary installation. It is enough to cook various kinds of foods and two sets of meals for four persons in one day. This system can be installed at a fixed place for the whole cooking period, and thus, it's able to be integrated into the wall of the kitchen or wall of a room in a building. This system can be used without going outdoor under the sunshine.

As mentioned above, this is a non-tracking type cooker and has a non-imaging line-axis asymmetric CPC for integration in the vertical facade. This is designed for Algerian Sahara region and is shown in Fig. 17. If this solar cooker is fixed in the building south wall and its opening rear side is in the kitchen, then it acts more user friendly [45]. One of the key features for the concentrating solar thermal systems is that they are aimed at building application with a wider acceptance angle for the requirement of the static installation. In this case, CPC as a typical low-concentrating ratio concentrator is a good choice. Fig. 18 [46] shows the structure of the typical CPC with the heat pipe located in the base center for the concentrating solar thermal application. The involute of the CPC is expressed as:

$$
\left\{\begin{array}{l}
X=\frac{d}{2}(\sin \varphi-\varphi \cos \varphi) \\
Y=\frac{d}{2}(\varphi \sin \varphi+\cos \varphi)
\end{array}\right.
$$

\section{Fig. 17}

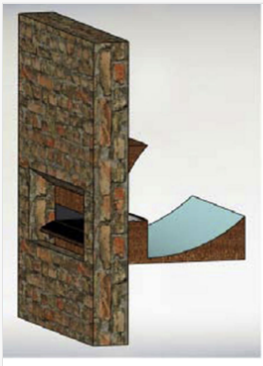

a: Internal side

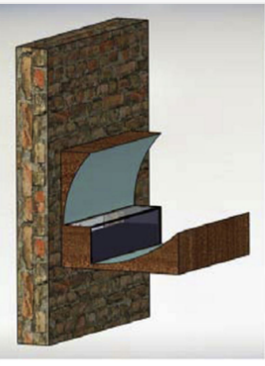

b: External side

Schematic sketch of the novel solar cooker integrated into building wall [45].

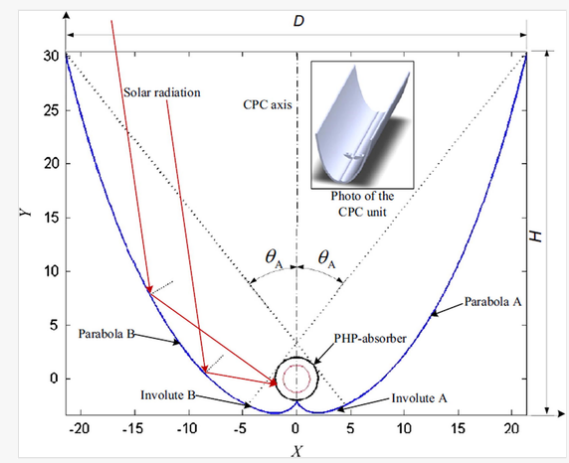

Geometry and dimension of the typical CPC with the heat pipe located in the center for solar thermal application [46].

For $0 \leqslant \varphi \leqslant 90^{\circ}+\theta A$

The parabola line is given by: 
For $90^{\circ}+\theta A \leqslant \varphi \leqslant 270^{\circ}+\theta A$ were

$$
A^{*}=\frac{\frac{\pi}{2}+\theta A+\varphi-\cos (\varphi-\theta A)}{1+\sin (\varphi-\theta A)}
$$

where $\varphi$ is angle between $\mathrm{X}$-axis and incident ray. $\theta A$ is CPC aperture angle.

Ratismith et al. [47] proposed a tilted-tough collector arrangement. The formation process of this kind of new CPC is shown in Fig. 19, where Fig. 19 (a) is the traditional compound parabolic concentrator, and its orientation inwards at $15^{\circ}$ angle as illustrated in Fig. 19 (b) will be the tilted-tough collector. Fig. 20 illustrates the characteristics for the incidence angles varying between $0^{\circ}$ and $60^{\circ}$. From the results, it was found that this tilted scheme smooths intercept factor (the ratio of the number of incident rays entering absorber plate to the number of incident rays entering trough aperture) as compared with the conventional $\mathrm{CPC}$ and it is worth noting that it still keeps a value of $28 \%$ at $60^{\circ}$ incidence angle at 4 p.m. They further conducted the whole-day experiment for this new nonconcentrating collector, the results of which revealed that the efficiency of this design has shown an increase of about $20 \%$. The comparison experiment with a non-concentrated system having identical tubes confirmed that the output temperature and output solar power of the concentrator can achieve the increase with a factor of $1.7 \times[48]$.

\section{Fig. 19}

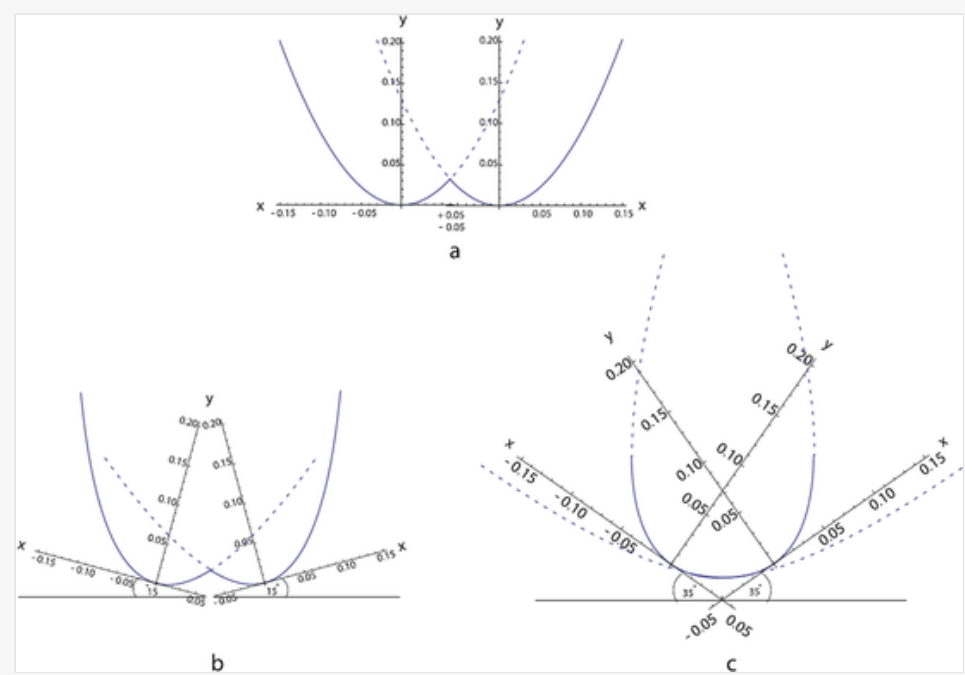

(a) The two parabolic trough shapes intersecting at the same point; (b) the titled CPC by rotating the parabolas inwards; (c) Rotating the CPC inwards until the base is flat [47]

\section{Fig. 20}

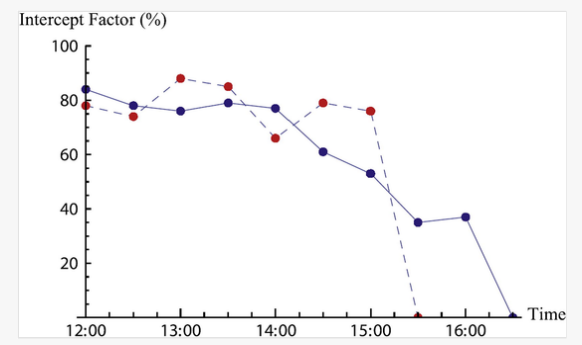

The intercept factor of the three-compound-parabolic trough collector as a function of the incidence angle of sunlight. Dashed curve for the traditional CPC, continuous curve for the titled CPC [47].

Thus, the advantage of the tilted arrangement is the high manifold temperature and as a result, higher temperatures can be obtained due to the concentration of radiations and additionally, fewer collector tubes are required to collect given insolation. The relatively higher acceptance angle can confirm the solar energy collection time throughout the day, which will be beneficial for building integration. Practically, a department in Bangkok installs 512 SUNDA-Seido1 tubes that occupy $130 \mathrm{~m}^{2}$ of roof space and power a 45 Kilowatt absorption chiller for air-condition purpose [47]. 
$\mathrm{Xu}$ et al. [46] reported a novel collector that integrates a closed-end PHP (pulsating heat pipe) and CPC (Fig. 21). Through the experiment testing (on building top in Beijing city of China), this design shows an efficiency of 50\% with a concentration ratio of $3.4 \times$ which confirms that the use of the CPC type solar collector on the buildings is reasonable.

\section{Fig. 21}

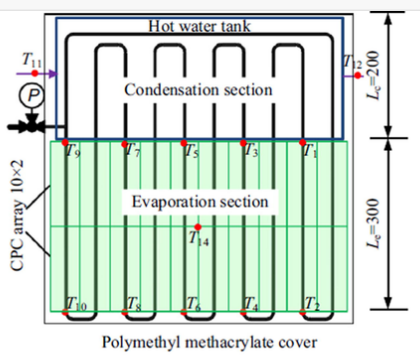

(a)

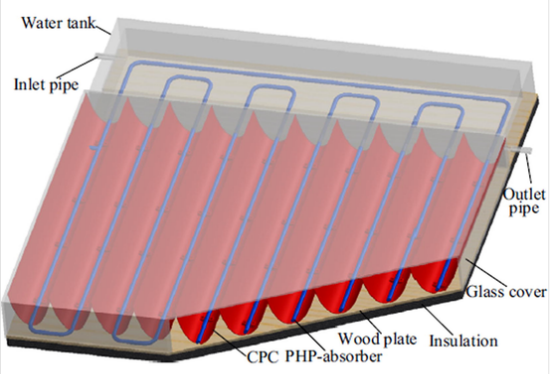

(b)

schematic diagram of solar collector integrated with CPC and PHP [46].

A detailed comparison of the concentrating thermal collectors with the use of the CPC are presented in Table 2 .

Table 2

(i) The presentation of Tables and the formatting of text in the online proof do not match the final output, though the data is the same. To preview the actual presentation, view the Proof.

Comparison of the concentrating thermal collectors with the use of the CPC.

\begin{tabular}{|c|c|c|c|c|c|c|}
\hline Researchers & Key feathers & $\begin{array}{l}\text { Concentration } \\
\text { ratio }\end{array}$ & $\begin{array}{l}\text { Working } \\
\text { fluids }\end{array}$ & $\begin{array}{l}\text { Highest } \\
\text { temperature }\end{array}$ & $\begin{array}{l}\text { Thermal } \\
\text { efficiency }\end{array}$ & Key findings \\
\hline Xu et al. [46] & $\begin{array}{l}\text { The integration of a closed-end pulsating heat pipe (PHP) and } \\
\text { a compound parabolic concentrator }\end{array}$ & 3.4 & Water & $75^{\circ} \mathrm{C}$ & $\begin{array}{l}\text { Up to } \\
50 \%\end{array}$ & $\begin{array}{l}\text { Thermal resistance of PHP absorber } \\
\text { reduces with increasing evaporation temp }\end{array}$ \\
\hline Zheng et al. [99] & $\begin{array}{l}\text { A combination of a compound parabolic concentrator solar } \\
\text { collector and a flat plate solar collector }\end{array}$ & 3 & Water & $52^{\circ} \mathrm{C}$ & $\begin{array}{l}\text { Up to } \\
60.5 \%\end{array}$ & $\begin{array}{l}\text { The new collector is more suitable to } \\
\text { provide low temperature hot water for } \\
\text { room heating in cold areas }\end{array}$ \\
\hline $\begin{array}{l}\text { Tripanagnostopoulos } \\
\text { et al. }[100,101]\end{array}$ & $\begin{array}{l}\text { The systems consist of single anddouble cylindrical horizontal } \\
\text { tanks properly placed in truncated symmetric and asymmetric } \\
\text { CPC reflector troughs }\end{array}$ & 1.12 & Water & $65^{\circ} \mathrm{C}$ & $\begin{array}{l}\text { Up to } \\
69 \%\end{array}$ & $\begin{array}{l}\text { Test results showed that asymmetric CPC } \\
\text { reflectors contribute to lower thermal } \\
\text { losses and two connected in series } \\
\text { cylindrical storage tanks result ineffective } \\
\text { water temperature stratification. }\end{array}$ \\
\hline Helal et al. [102] & $\begin{array}{l}\text { Consisting of a single cylindrical horizontal tank placed in a } \\
\text { reflector composed of three parabolic branches is designed }\end{array}$ & 1.05 and 1.12 & Water & - & $\begin{array}{l}\text { Up to } \\
65 \%\end{array}$ & $\begin{array}{l}\text { Higher thermal efficiency was obtained } \\
\text { compared with other similar systems }\end{array}$ \\
\hline Kalogirou [103] & $\begin{array}{l}\text { Fully developed cusp concentrators with cylindrical receivers } \\
\text { are integrated together for hot water production }\end{array}$ & 1.47 & water & $86.2^{\circ} \mathrm{C}$ & - & $\begin{array}{l}\text { The initial cost of the system is } 13 \% \\
\text { cheaperas compared with the flat-plate } \\
\text { collector system of the same aperture area }\end{array}$ \\
\hline Xiaodi, et al. [104] & $\begin{array}{l}\text { A new solar boiling water system with conventional vacuum- } \\
\text { tube solar collector as primary heater and a multiple curved } \\
\text { surfaces compound concentrator as secondary heater }\end{array}$ & 2 & water & $80^{\circ} \mathrm{C}$ & $71 \%$ & $\begin{array}{l}\text { The performance of the system has been } \\
\text { found closely related to the solar radiance }\end{array}$ \\
\hline Oommen and & A CPC collector with $\mathrm{V}$ grove as the concentrator and & 2.17 & water & $66^{\circ} \mathrm{C}$ & $60 \%$ & Lower thermal loss and the gap losses can \\
\hline
\end{tabular}




\section{Building integrated concentrating solar daylighting (BICSD)}

\subsection{The demand for BICSD}

It was estimated by the Energy Information Administration (EIA) that the consumption of the electricity for lighting for the residential and commercial sectors in 2016 was 279 billion $\mathrm{kWh}$, which was around $10 \%$ of the total electricity consumption by these sectors and around $7 \%$ of the total electricity consumption in the United States [49]. Natural daylighting is able to provide a healthy and efficient illumination environment for the human activity, which will also reduce the building energy consumption.

The solar cell transforms a portion of the incoming sunlight into the electric energy and rest is in form of heat dissipation. There are several spaces among the concentrators that allow direct light transmission, which can provide daylighting for the interior of the building [20]. The above-mentioned PV/T/D can get outstanding light control at the time of noon. The space between separate units may vary depending upon the light requirements. The distance between individual units must be enhanced with regard to the limitations of the required daily lighting and the reduction of ohmic losses due to the increased connection length [50].

\subsection{Types/Applications/Structures of BICSD}

A standard multi-sectional facade, including the upper part, main center part and spandrel, was studied by Chan et al. [51]. The upper part couldn't get the direct sunlight into the interior space deeply. The middle part allows the controlled admission of direct sunlight. The heat resistance requirements for the test site are satisfied with a spandrel bottom. Their research focused on the effect of a combination of 3 solar protection devices and light fixtures (bulbs, roller shades and blinds) in a combined way. They evaluated 2 climates and 2 orientations that act as the primary research to support in the development of multiple facade guidelines. Fig. 22 demonstrates the concept and shows the difference between the standard facade and the cross section of the facade. Four situations given in Table 1 were considered. Situations 1 and 2 are the fundamentals for comparison between standard and multiple facades. Their features and controls mentioned in Table 3 are chosen by using parametric studies. Fig. 23 shows representative light transmission profiles. The results show that the "no shading" scenario cannot be considered in actual locations because visual discomfort reaches to $75 \%$ even at $2.74 \mathrm{~m}$ far away from the window. So, this situation is just used for reference. Other situations are considered to keep the frequency of visual inconvenience of a certain amount that is less than 3\%. Situation 4 (roller shades and light shelf) is $24 \%$ higher than the continuous daylighting of situation 2 (roller shades only) where continuous daylight autonomy (cDA) for scenario 2 is $64.61 \%$. Meanwhile, situation 4 is better than situation 3 in the sense of effectively directing the light for the same geometry. In addition, it has been found that multiple facade cases (blinds and light shelf) are more suitable for occupants, as a more uniform distribution of light and visual environment of the interior space would be available.

\section{Fig. 22}
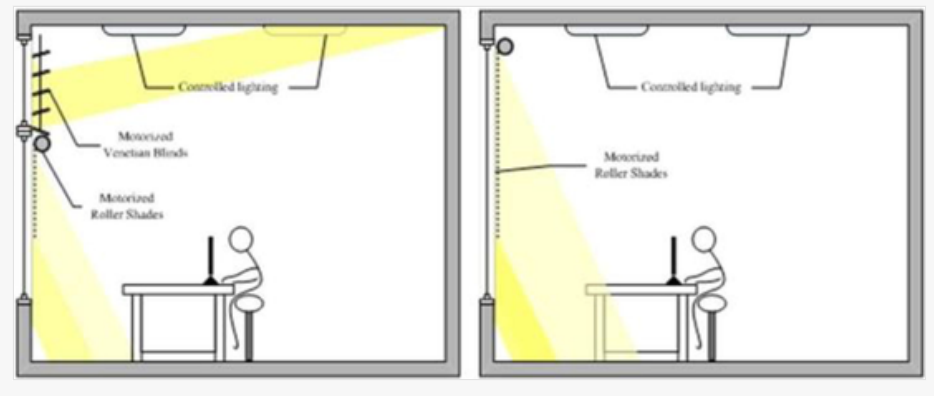

Multi-Sectional Façade (left); Traditional façade (right) [51].

Table 3

(i) The presentation of Tables and the formatting of text in the online proof do not match the final output, though the data is the same. To preview the actual presentation, view the Proof.

Properties of facades and controls used in the simulation [53].

\begin{tabular}{|l|l|l|l|}
\hline \multicolumn{1}{|c|}{$\begin{array}{l}\text { Type of } \\
\text { shading }\end{array}$} & Properties & Control \\
\hline Scenario & No Shading & - & - \\
\hline
\end{tabular}




\begin{tabular}{|c|c|c|c|}
\hline $\begin{array}{l}\text { Scenario } \\
2\end{array}$ & $\begin{array}{l}\text { Roller Shades } \\
(2 \mathrm{~m})\end{array}$ & Transmittance $=5 \%$ Openness Factor $=1 \%$ Front Reflectivity $=70 \%$ & Effective illuminance control Setpoint $=2500 \mathrm{~lx}$ \\
\hline \multirow{2}{*}{$\begin{array}{l}\text { Scenario } \\
3\end{array}$} & $\begin{array}{l}\text { Roller Shades } \\
(1.1 \mathrm{~m})\end{array}$ & Same as Scenario 2 & Effective illuminance control Setpoint $=1500 \mathrm{~lx}$ \\
\hline & Blinds $(0.9 \mathrm{~m})$ & $\begin{array}{l}\text { Slat Front Reflectivity }=80 \% \text { Slat Front Specularity }=80 \% \text { Slat Back } \\
\text { Specularity }=0 \% \text { Slat Width } / \text { Gap Height }=5 \mathrm{~cm}\end{array}$ & $\begin{array}{l}\text { Low-profile angle: cut-off angle controlHigh-profile angle: light-redirect } \\
\text { controlDarkness override }=3000 \mathrm{~lx}\end{array}$ \\
\hline \multirow{2}{*}{$\begin{array}{l}\text { Scenario } \\
4\end{array}$} & $\begin{array}{l}\text { Roller Shades } \\
(1.4 \mathrm{~m})\end{array}$ & Same as Scenario 2 & Effective illuminance control Setpoint $=2500 \mathrm{~lx}$ \\
\hline & Blinds $(0.4 \mathrm{~m})$ & Shelf Reflectivity $=80 \%$ Shelf Specularity $=80 \%$ Shelf length $=1 \mathrm{~m}$ & $\begin{array}{l}\text { Low-profile angle: cut-off angle controlHigh-profile angle: light-redirect } \\
\text { controlDarkness override }=3000 \mathrm{~lx}\end{array}$ \\
\hline
\end{tabular}

\section{Fig. 23}

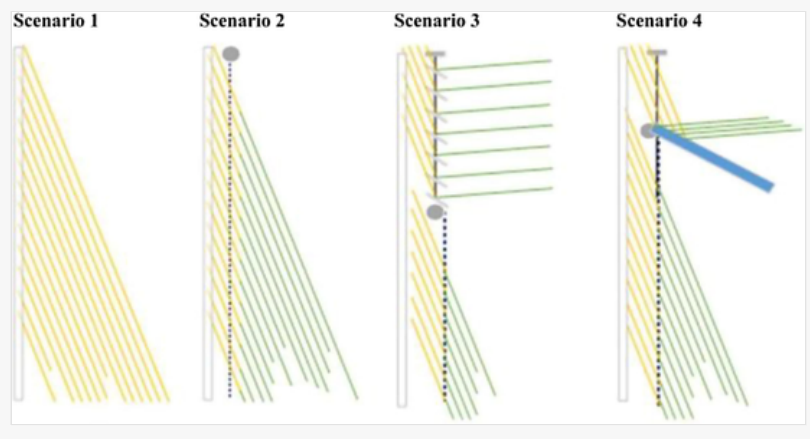

Distribution of transmitted light (and solar radiation) for 4 Scenarios [51]

Zhu et al. [52] designed a new window as concentrating daylighting for building curtain wall integration which is based on the Fresnel lens. The main construction and additional components of the concentrating module are shown in Fig. 24. In order to improve light reception namely optical efficiency, the secondary glass concentrator of $\mathrm{K} 9$ is provided in the form of a reverse trapezoidal square cone. Incoming solar radiation first reaches a secondary concentrator and then captured by a receiver consisting of ceramic substrates of aluminum oxide and concentration cells. As clearly described above, the whole system has a high solar energy usage ratio for solar radiation is either used for the electricity generation or for the daylighting. A new two-axis reserve control structure is intended for energy saving, the geometric structure of which is presented in Fig. 25. Fixed (white) and active (green) brackets are attached to the control levers with combined bearings that act as connecting nodes. Each lever is attached to the module to obtain a concentrating matrix.

\section{Fig. 24}
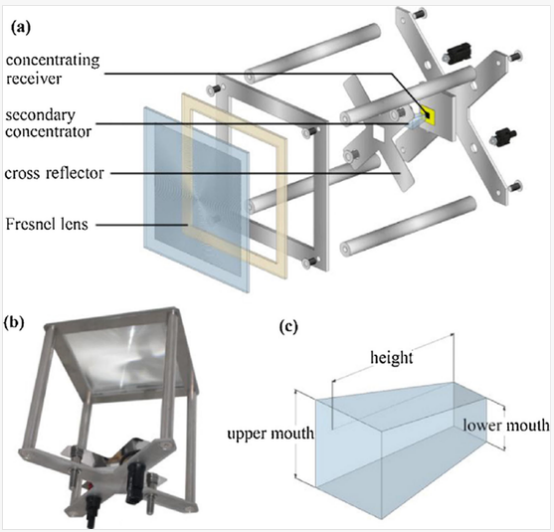

Design of the to-be-integrated concentrating module (a) Exploded view. (b) Real model. (c) Secondary concentrator [52]. 


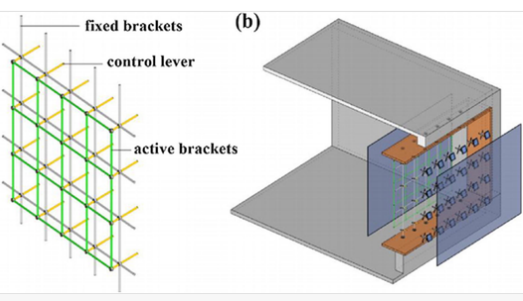

Dual-axis linkage control structure for building integration (a) control structure. (b) Exploded view [52].

Key findings draw from authors' simulation work confirmed the concept of the concentrating array. It can both act as the daylighting and electricity resource for the buildings. When the focusing array is in the operational state, the daylighting on room floor behind the window is simply 5 to $10 \%$ lower than that when focusing array is not working or the focusing array is not present. On the basis of dielectric crossed compound parabolic concentrator (dCCPC), Tian et al. designed a skylight for home use [53]. The daylighting simulation was directed by Radiance and Daysim and then is moved to EnergyPlus to forecast the yearly energy use of the building by using the dCCPC. When dCCPC is used, energy is saved as compared to low-E and traditional double glazing. It has been found that the $\mathrm{dCCPC}$ is more appropriate for cities that have long summer season such as Manila, Bangkok, Los Angeles and Miami. In these areas, the thermal load is reduced to $23 \%$ and total energy savings are $13 \%$.

\section{Combinations}

\subsection{Building integrated concentrating photovoltaic/thermal (BICPV/T)}

\subsubsection{The demand for BICPV/T}

The technology of building integrated photovoltaic systems (BIPV) is one of the main areas of photovoltaic applications [54]. This technology offers a cohesive design, construction and sustainable solution for the built environment [55]. However, in the BIPV, the photovoltaic cell performance degrades obviously due to cell temperature increase. To solve this problem, the cooling system could be used to recover heat from PV cell. Though, instead of wasting this heat in the environment, it is possible to use it again. Inspiring from this idea, since the 1970's, numerous studies have tried to explore the use of heat-generated by photovoltaic as they became known as PV/T solar collectors. During the 1980s, these studies were largely shelved but, due to concerns about growing energy sources and their use, PV/Ts started to gain more attention [56]. In order to collect solar energy efficiently, integrated photovoltaic combined heat and power systems are particularly good as radiation is transformed into electric energy and heat energy [57]. PV/T systems have the capability to produce more power per unit area as compared to simple PV systems. Collectors are available with lower cost of manufacturing and installation. PV/T is mostly suitable for the applications where both the electric power and heat energy are required and for small roof space [57].

Building Integrated Photovoltaic Thermal System (BICPV/T) has much potential to be the key source of renewable energy in the metropolitan area [58]. Over the past decades, numerous PV/T studies have been conducted independently, which have resulted in the idea of integrating PV and heat into one module [41] and different system designs.

This review paper has investigated the effect of various parameters on the performance of the photovoltaic thermal collectors. Additionally, different approaches to investigate the PV/T systems such as numerical, analytical and experimental models have been covered. PV/T systems that normally use water and air as heat withdrawal fluid. Various influencing parameters like glazing, mass flow and impact of the absorber \& types of construction have been considered in detail. As a result, the exergy analysis showed that the unglazed collector is superior in the total (electrical and thermal) exergy. But, glazed collectors are recognized as better systems by energy analysis. It is assured that PV/Ts are vital systems for future applications, but there are no significant discoveries to reduce PV/T collectors' cost.

The attractions in the PV/T system are:

a. Dual-Purpose: One device can generate both electric power and heat energy;

b. Efficient \& Flexible: The combined systems efficiency is greater than the case when using these systems separately and it is particularly good for BIPV when the roof space is small

c. Having an extensive use: Its output can be further used for both cooling (desiccant cooling) and heating purposes depending upon the weather. It is practically appropriate for household use.

d. Cheap and Practical: It can be integrated easily with buildings without requiring major modifications. On the other hand, replacement of roof material by PV/T can decrease the payback time [57].

PV/T systems were used with solar cells that were previously considered as expensive applications. Usually, the PV/T systems can be classified into 4 types: concentrated collectors, flat plate systems, hybrid (water/air) collectors, and BIPVT. The PV/T technology has a lot of diverse applications like water heating, room heating, Sun drying, building integrated skins (facades), etc. [1].

For the water and room heating applications, the solar collector is connected to the PV module, and the heat from the rear side of the collector is used for heating. Huge attention is paid to the application of PV as a facade by various researchers. Limited space available for thermal and electric power generation units in city areas encourages PV/T as well as encourages their integration in the buildings. Setting up of PV in vertical facades is particularly suitable for high latitudes with low solar height [59]. 


\subsubsection{Types/Applications/Structures of BICPV/T}

Fig. 26 shows that the CPC concentrates the radiation connected to photovoltaic. The fins presented on the back of the PV panel helps in efficient transmission to air and increase the system performance. Thermal receiver is generally connected with the back of the module. The rest of the parts, such as glass, insulation part, and absorber are illustrated in Fig. 26. The University of Delaware employed first air hybrid collector. This collector is installed on the roof of a building, which is also called as the "Solar one" home in the university. Air is used in the collector as a cooling agent [1].

\section{Fig. 26}

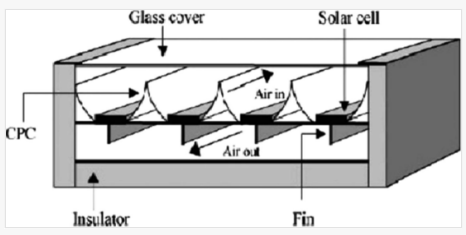

Schematic of a double PVT solar collector with CPC and fins [1].

Kribus et al. [60] suggested a miniature concentrated PV (MCPV)/thermal system that could generate both thermal and electric energy. It was created to deliver energy to neighboring users. By analyzing the system, it shows a production of 140-180 Watt of electric power and 400-500 Watt of thermal power. The cost of developing MCPV systems was low in comparison to the current flat panel. The efficiency of the system for the electricity production, heat and CHP is shown in Fig. 27. The ranges of temperature for possible thermal uses are also given. It can be said that concentrated systems could concentrate additional radiation on photovoltaic cells, which leads to better results as compared to flat plate systems.

\section{Fig. 27}

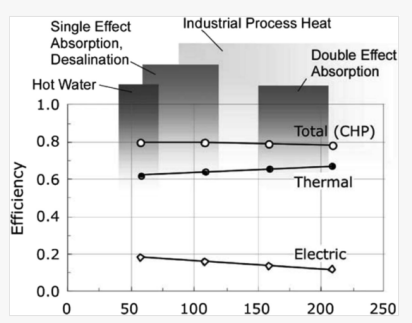

The variation in the overall system efficiency for production of electricity, heat, and CHP with the coolant outlet temperature is shown. Temperature ranges for potential thermal applications are shown as well [60].

Sonneveld et al. [61] designed a greenhouse with linear Fresnel lenses in lid that acts as a concentrating PV system (CPV). The CPV integrated with room roof naturally has capacity to concentrate all direct sun rays, while simultaneously providing a way for diffused solar radiation cone into the greenhouse system. All direct radiations are concentrated 25 times on the PV/T and transformed into heat and electrical energy. The tracking system was used in order to keep the $\mathrm{CPV} / \mathrm{T}$ module to be in the position through two motors and steel cables. The accumulated heat can also be stored and then used for heating in winter. The produced electricity can be delivered to the electric grid, or can be used for additional cooling with the pads and fans and/or can be used for the desalination. Experimental results showed that it's an excellent system for temperature control and lighting in the greenhouse and roof construction, with production of current and heat at the same time. It is illustrated that the energy contribution is enough for the needs of heating greenhouses in northern EU regions.

A novel system consisting of combined CPV based on static linear Fresnel objects and PV/T was fabricated and evaluated in a $6 \times 6 \mathrm{~m}$ greenhouse. The system of lens was separated directly from diffused radiation. The direct radiation was redirected to PV/T, and the diffused part of radiation was used to effectively light the crops. The system can be upgraded by using an AR coating to a double glass structure, laminating Fresnel lens to glass, and using more effective by-pass diodes (Schottky) in parallel connection to photovoltaic cells. These diodes will decrease the impact of shaded strips of glass bars. After these enhancements, the system will not require help from fossil fuel resources and will even deliver excess electricity to the grid [61]. A prototype of double pass PV/T collecting system with $\mathrm{CPC}$ and fins was proposed, fabricated and evaluated under different operating conditions. The absorber of hybrid PV/T being investigated has PV cell arrays for production of electric power, a CPC for increasing the intensity of radiation, and the fins present on back to enhance heat transmission to air. Air enters from the top channel created by glass and PV panel and warms up from the sun. Then it goes to the lower channel created by rear plate and panel. CPC concentrates radiation on the photovoltaic cells. The fins present on the panel backside improves heat transmission to air and increases the system performance. They concluded that the increase in air temperature decreases the electricity generation in hybrid PV/T, which suggests that the temperature must be as low as possible. In other words, the system must effectively use warm air for some other purposes. Therefore, a compromise between the maximization production of electric power and hot air is important. The use of hybrid PV/T, CPC and fins at the same time can cause a significant increase in energy production and decrease photovoltaic electricity costs.

Chemisana and Rosell [62] designed a transmissive Fresnel reflector that meets the needs of integration of concentrated PV, thermal or hybrid PV/T in buildings. The device focuses the radiation towards the static receiver with the use of reflectors that rotate conjointly. All axes of rotation are coplanar and parallel. The 
following conclusions were formulated by analyzing different Fresnel transmission systems: the control of Fresnel transmission systems is possible by one driver, which greatly improves practicability and reduces costs. The efficiency of the system is dependent upon angle of incidence. The mirror ratio is described as reflector surface needed for the unit area of the aperture and allows estimation of the financial feasibility of test device. With the increase of the incident angle, the non-uniformity of light profile increases. The maximum profile displacement is observed when the sun moves from the center of the receiver, but its value is less than $2 \mathrm{~cm}$ for largest incident angle. It has been found that the system efficiency is reduced by shading and blocking phenomenon. Shading phenomenon refers to the interruption in the rays prior to reaching mirror and the blocking phenomenon refers to the interruption in rays after reflection from the mirror. Fig. 28 shows a 3D view of proposed system that better understands the global look of the concentration device [62].

\section{Fig. 28}

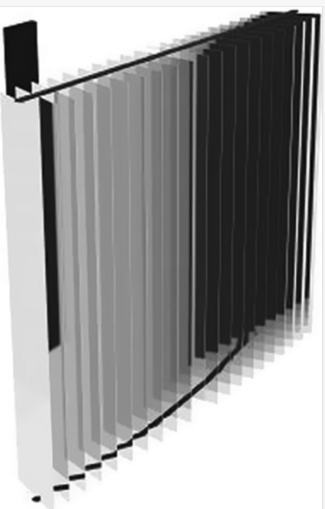

$3 \mathrm{D}$ image of the system [61].

Cappelletti et al. [63] has introduced an electro-thermal solar system that has adopted a 20× semi-parabolic mirror concentrator designed for use in buildings. The thermal receiver is attached to the rear plate of the PV cell, and the fluid circle flowed in thermal receiver recovers heat. Monoaxial sun tracking is allowed by linear focus. The proposed device is analyzed numerically with use of experimental data. Small size and linear focus and other architectural designs make the integration of proposed device into the facades or roofs of new and old buildings feasible where they help in automatic production of a part of the total required energy.

Davidsson et al. [64] developed a multifunctional PV/T window that is integrated into the building. Photovoltaic cells were placed on absorbers, which were positioned in the window behind glazing. Tiltable reflectors are designed in such a way as to focus solar radiation on solar cells to improve PV performance. Reflectors provide the ability to control the radiation that is transmitted to the building. Insulated reflectors also decrease heat losses through window. A simulation model for electricity and hot water production was fabricated and simulation results showed that in comparison to the vertical flat PV, the proposed window produces annually about 35\% more electricity per unit area of the cell. The solar window shown in Fig. 29 is made of solar thermal absorbers where photovoltaic cells are laminated. Absorbers are built in the interior of a standard window, saving the frames and glazing and reducing the overall construction costs. In order to reduce the area of photovoltaic cells, reflectors are positioned behind the absorber. If the reflectors are tilted into the vertical direction, the sunlight focuses on the absorber. If the reflectors are inclined in a horizontal direction, sunlight is allowed to enter in the building for passive heating. This shows that reflectors placed in closed position increases radiations on cell, reduces heat loss and it also acts as a sunshade. This window was in $23^{\circ}$ direction from the south to east. The simulation results revealed that the incoming sunshine was clearly affected by the shadow and transmission. With the low tilted solar window on the roof, it captures more diffused solar radiations than a wall-mounted PV, as the window could see a greater part of diffused radiations from the sky. This is clearly shown in Fig. 30. If heat and electric energy are required, reflectors will remain closed. For this condition, the window acts more like as wall. In summer season, when the solar altitude is high, a big part of radiations goes to the absorber directly. At that time the reflector can partially open and solar window provides electricity, heat energy, and light. This is maybe the best usage of a window. It is important to use diffused radiations. It was found that vertical collectors and windows at high latitudes have higher energy efficiency than at low levels. The PV/T hybrid window model, positioned vertically in the wall, generates approximately the same quantity of electricity as the roof integrated PV module per unit area of the cell. At the same time, they produce approximately the same amount of heat energy per unit of absorption surface compared to a collector installed in the same roof inclined by $20^{\circ}$. 

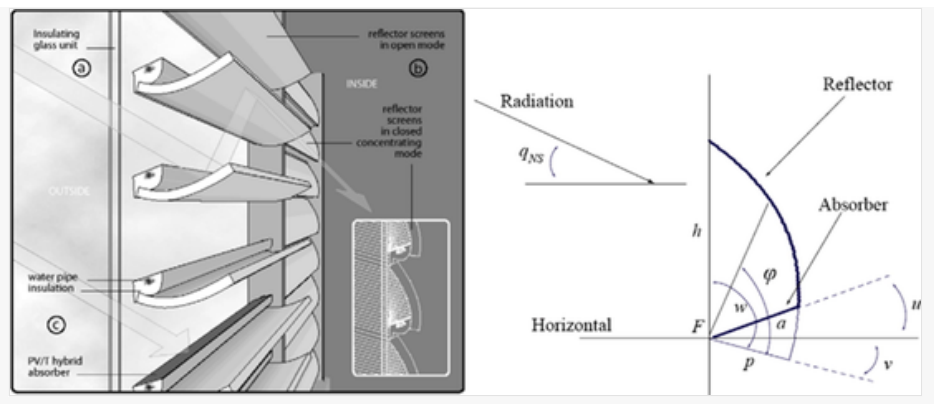

Left: the solar window. Right: illustration of the parabolic reflector and the absorber [64].

Fig. 30

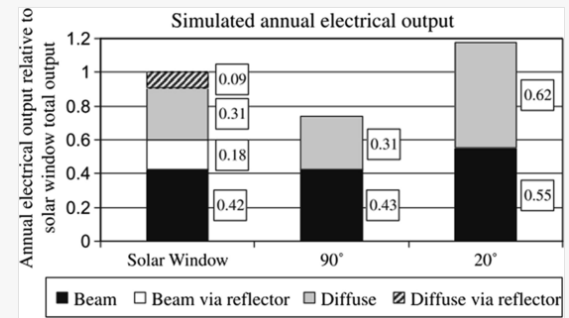

The annual electrical output from the prototype solar window and from two flat PV-modules on a wall at $90^{\circ}$ tilt and on a roof at $20^{\circ}$ tilt [64].

Concentrating PV wall element, $\mathrm{Cu}$ (In, Ga) $S_{e 2}$-based modules, aluminum reflectors and insulations for incorporation into building were fabricated and tested by Brogren et al. Fig. 31 shows the prototype of the PV system with parabolic concentrations for wall incorporation [65]. The wall element described here is designed for easy installation as it has insulation and it is modular. The collector has a hybrid PV/T absorber. The system comprises parabolic aluminum reflectors, photovoltaic panels and expanded polystyrene insulators (EPS). Because the insulating material is attached directly to the back of the reflector sheet, the facade element can serve as an integral part of the building cover [66]. The CPC geometry shown in the research by Gajbert et al. [66] is asymmetric and includes only one upper reflector. This simple and optimized design save the cost of the system, meanwhile, generate more electricity production. The aim of their work was to optimize the geometry of a wall mounted solar collector for working in latitude areas of approximately $60^{\circ}$ wide. The setting is shown in Fig. 32. Considering the fact that the increase in PV cell temperature will negatively affects the PV performance, and decrease the overall system efficiency. The most effective way to remove or reduce this impact is by cooling the solar cells using heat transfer liquids to proper temperatures (about $30-55^{\circ} \mathrm{C}$ depending on the type of cell). Active cooling with water produces hot water for preheating water or heating the premises. They considered that if a PV/T absorber is obtained, the demand of heat energy and heating pattern should also be taken into account for collector designing [66].

\section{Fig. 31}
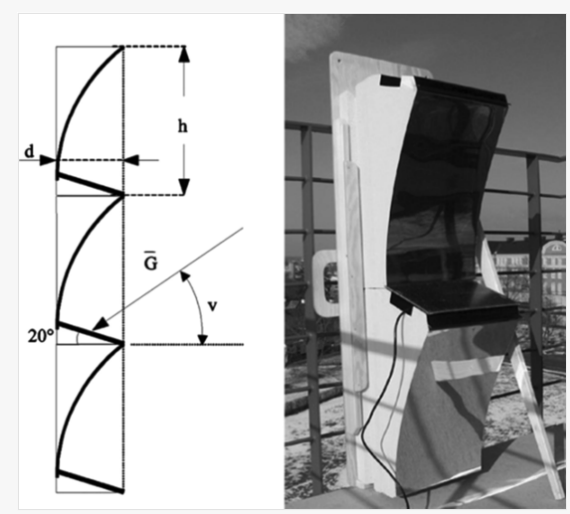

Section of a concentrating photovoltaic element for wall integration, with a concentration ratio of $3 \times \mathrm{G}$ denotes the incoming irradiation and $\mathrm{v}$ is the effective solar height. The photovoltaic module is tilted forwards by $20^{\circ}$. The depth, d; of the wall element is $180 \mathrm{~mm}$ and the opening of a single concentrating element, h; is $550 \mathrm{~mm}$ [65]. 


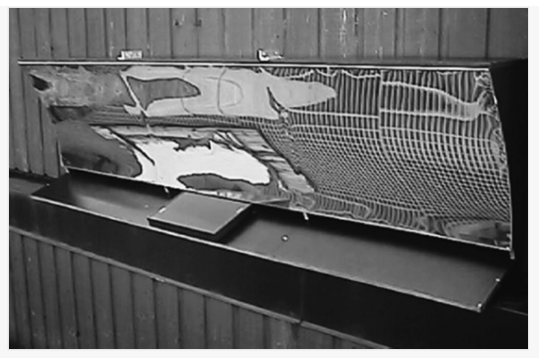

Photograph of a ST5 photovoltaic module from Siemens in a concentrating reflector system. An identical reference module was mounted in the vertical plane of the aperture [66].

A stationary flat diffused reflector of a thin aluminum was connected with a rigid wood panel and adapted to the sun (Fig. 33). This has improved radiation falling on the photovoltaic panel, as it ensures uniformly distributed reflected radiation on the photovoltaic surface [67]. Brogren and Karlsson [59] conducted a research on a low-concentrated water-cooled type PV/T for integration in buildings. They designed and evaluated these systems with static parabolic reflectors for usage on ground or integration of photovoltaic systems in building facades at high latitudes. The system combines PV/T with cheap aluminum (Al) reflectors with a concentration of $4.3 \times$ and offers good potential for a significant increase in energy production from a particular area of solar cells and a reduction in the cost of photovoltaic power. It has been found that at water temperature of $50{ }^{\circ} \mathrm{C}$ the yearly electric power generation was significantly higher, about twice, and the heat energy production was higher, about 3-4 times in comparison to the conventional non-concentrating vertical PV [59].

\section{Fig. 33}

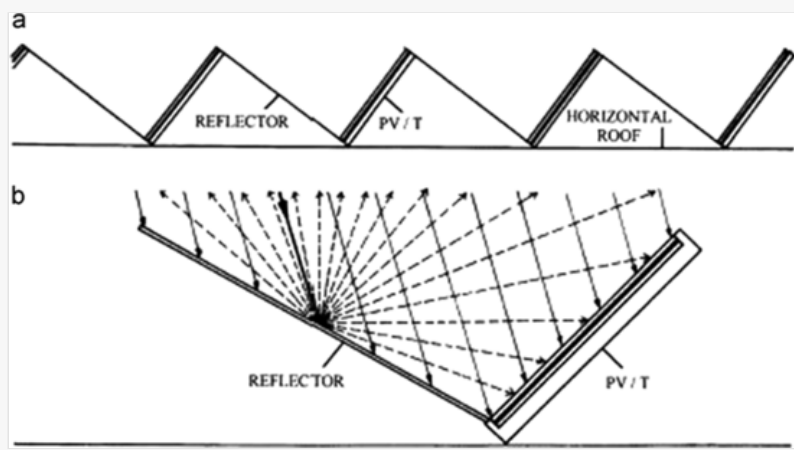

PV/T system with booster diffuse reflectors: (a) horizontal building roof system installation; (b) indication of diffuse reflected radiation on the PV panel [67].

The first model of the hybrid CPV/T ANU-Chromasun Micro-Concentrator (MCT) was mounted on the roof of Australian National University, Australia, by Vivar et al. [68] (Fig. 34). The MCT system's electrical and thermal properties, including current and day-to-day checking, shows that the combined system efficiency can exceed $70 \%$. During the day, the average electric and heating efficiencies were $8 \%$ and $60 \%$. The Chromasun Micro-Concentrator (MCT) is a glass-encased, lightweight framework with a low wind load factor and is specifically designed for roof applications.

\section{Fig. 34}

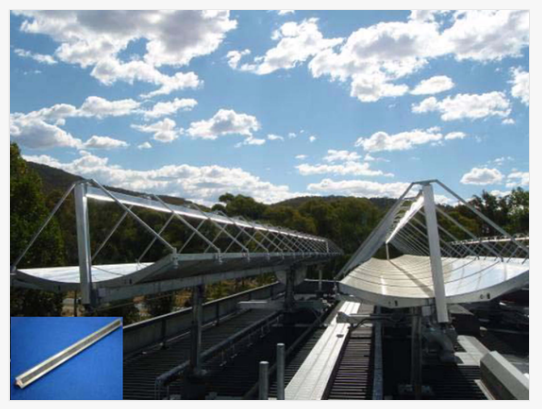

The CHAPS PV- Thermal hybrid concentrator on the roof of Bruce Hall (Canberra, Australia); and detail of the actively- cooled receiver [68].

The approach of designing a cycloidal transmissive Fresnel concentrating system that could offer a specific focal line was designed by Feng et al. [69]. A concentrated PV/T with the Fresnel concentrator was constructed. Optical simulation was performed to get the efficiency for various tracking errors and axial incident angles. Further, the temperature distribution on the receiver, the outputs of the electrical power and heat energy of concentrated PV/T, efficiency of combined use of electrical and thermal energy, etc. are tested. The test results under the clear weather revealed that the maximum Efficiency of electricity production is around $18 \%$ at time of noon, and maximum heat receiving rate of cold water is approximately 45\%. From 11:00 to 13:00, total efficiency of heat and electric energy can exceed 55\%. The efficiency of this concentrated PV/T with the transmissive Fresnel concentrator is analyzed. System efficiencies, 
thermal and electric output are also compared for clear and hazy weather conditions. It is clear from the results that the hazy weather conditions have a large impact on the electricity production, but it has less influence on the heating output. Fresnel lens with a cycloidal outer side has an improved ability to withstand climatic factors (i.e. gale or sand dust) and protect the inner structure. Center of gravity of the lens with a cyclic outer side can be designed close to the axis and it can reduce the energy use of the tracking. The operating principle is shown in Fig. 35. The experimental system consists of a transmissive Fresnel concentrator, photovoltaic cells of gallium arsenide, cooling water channels, thermocouples (K-type), temperature collector, irradiation meter, voltmeter (precision $\pm 0.1 \mathrm{mV}$ ), ammeter (precision $\pm 0.1 \mathrm{~mA}$ ), pump for cooling, and water flow meter, etc. [69].

\section{Fig. 35}

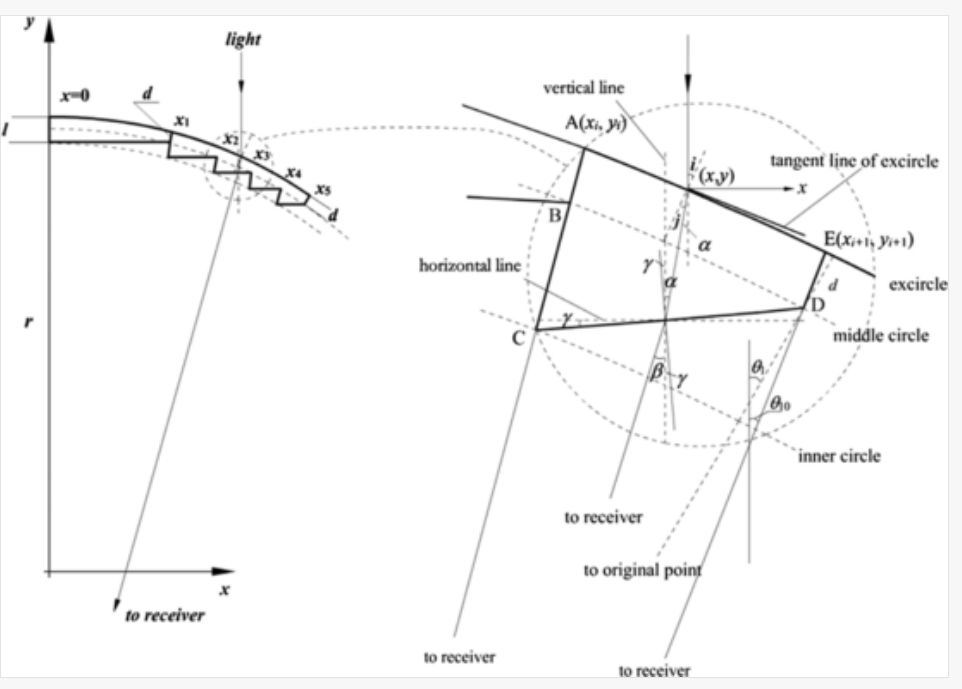

Fresnel lens with cycloidal outside surface [69].

On the basis of lens-walled CPC with air gap, Li et al. [70] made a concentrating PV/T system to deliver heat source for households. It differs from the usual $\mathrm{CPV}$ or $\mathrm{CPV} / \mathrm{T}$ because the static miniature concentration $\mathrm{PV} / \mathrm{T}$ does not require tracking. Therefore, it has many benefits.

$\mathrm{PV} / \mathrm{T}$ technologies offer tremendous potential for development as an innovation for the Swedish solar market. Gu et al. [71] evaluated the reference PV/T in Sweden using the Monte Carlo approach. Provided the estimated PV/T concentration size is $10.37 \mathrm{~m}^{2}$ and the capital value is $4482-5378 \mathrm{SEK} / \mathrm{m}^{2}(448.2-537.8$ $€ / \mathrm{m}^{2}$ ). It was established that the average values of LCOE (SEK/ $/ \mathrm{WWh}$ ), NPV (net present value, SEK) and PP (payback, years) for reference PV/T concentrator are 1.27 SEK/kWh (0.127 €/kW) SEK 18812.55 (1881.255€) and 10 years respectively. About $12 \%$ high risk was analyzed for PP during 25 -year lifetime. As per the NPV rule, positive NPV shows that the investment in the chosen PV/T will be gainful, as the earning exceeds the expected cost over its lifetime.

\subsection{Building integrated concentrating photovoltaic/ daylighting (BICPV/D)}

\subsubsection{The demand for BICPV/D}

The artificial lighting has been employed as supplementary lighting resource for a long term, but in fact it may have the negative effects on human health [72]. However, for nature daylighting, it can provide lots of benefits to the human health and even cure some of the medical ailments [73], which will also reduce psychological sadness related to the seasonal affective disorder [74].

The traditional PV module will prevent the sun-rays from entering the room. Compared with the traditional flat PV module, the concentrating PV technology offers more design imaginations for combing the natural daylighting, and the solar concentrators are usually made of the transparent material such as polymethyl methacrylate (PMMA). So the CPV module would allow a portion of "escape" sun rays into the room for daylighting, which means this portion of the sun rays cannot reach the PV for the power generation.

\subsubsection{Types/Applications/Structures of BICPV/D}

A 1-D model of transitional heat transfer, SPVHG was developed to assess the thermal aspects of the modules. In addition to heat energy transfer, energy generation and daylighting usage are also important parts of energy efficiency assessment of these modules for use in facades [75]. Using SPVHG model, along with energy production model and indoor lighting model, the energy efficiency of such facades is assessed in terms of electricity advantage. Total heat obtained by the facade for three different directions are shown in Fig. 36 [76]. The use of these systems on windows and other facades can produce energy and decrease heat gains to reduce the energy use of building air condition system. 


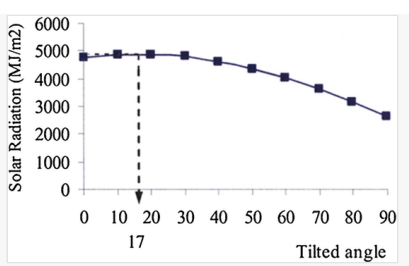

The total heat gains through semi-transparent PV facades [76].

Wu et al. [77] suggested the concept of an Integrated concentrated PV System for buildings (BICPV) named as 'smart window' that could address the challenges of energy-efficient constructions from the viewpoint of energy efficiency and use of renewable resources. The thermotropic layer changes the ratio of the light passing through it and dispersed from it. When the temperature of thermotropic is below the threshold switch temp. ( $\mathrm{T}_{\mathrm{S}}$ ), the thermotropic layer has a high transmission of $85 \%$, which offers the maximum of sunlight to enter in the room for lighting. While the temperature above the limit $\mathrm{T}_{\mathrm{S}}$ will result in a translucent layer with diffused reflectivity, in which case the thermotropic layer could disperse most of the sunlight passing through glass with the following transformation of dispersed light into the electric power. This conversion is done by PV cells optically connected around the glazing edges as displayed in Fig. 37. In Fig. 38 [78], it can be observed that below $\mathrm{T}_{\mathrm{s}}$, transparency is appropriate for the glazing purpose and thermotropic effect of HPC within membrane is still working above $\mathrm{T}_{\mathrm{s}}$.

\section{Fig. 37}
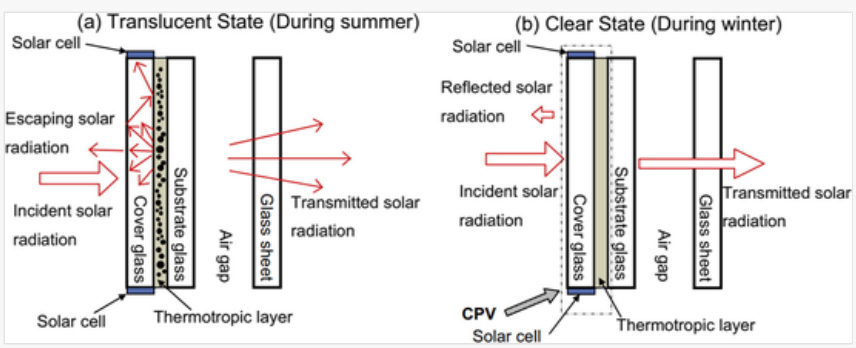

Cross-section view with working principle of the proposed concentrating PV [77].

\section{Fig. 38}

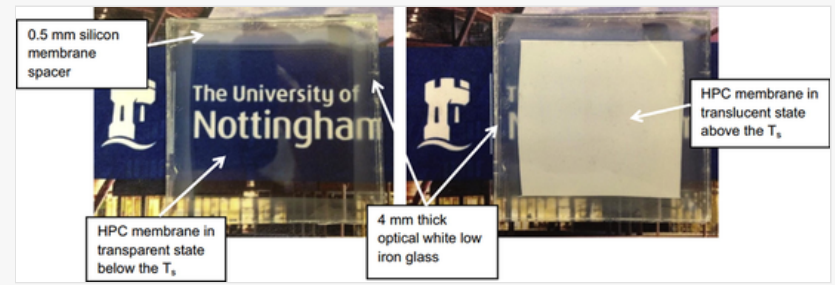

Photograph of the thermotropic layer below Ts at room temperature (left photograph) and heated above the Ts (right photograph) [78].

Fig. 39 highlighted the optical performance of a smart CPV at different incident angles of sun radiation and a lowest efficiency of $25 \%$ for a smart CPV window was observed. Fig. 40 shows transmissions and reflections for the smart CPV window. By increasing the temperature, there was an apparent decrease in the transmission value, which shows the function of reducing the amount of solar radiation in the building but by increasing the winter's value, we can achieve heat management for buildings so as to save the total energy consumption.

\section{Fig. 39}

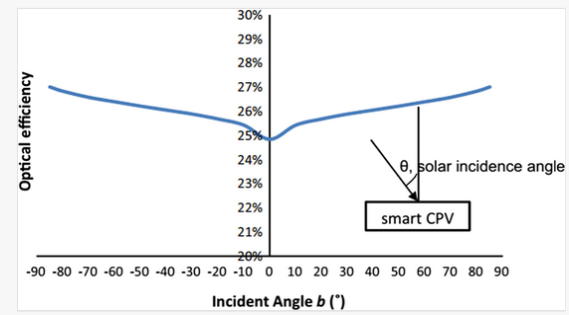




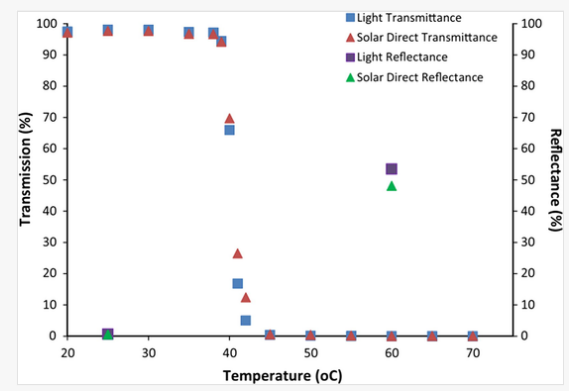

Averaged transmittance and reflectance data for the "smart window" with the increasing temperature [77].

A Hybrid Lighting-CPV which combines CPV module with lighting guides is presented by Núñez R et al. [79] in 2012. It consists of a hybrid CPV module where a small part of the receiver area is used to inject light in optical guides. It is only needed to transport the solar energy and not to convert first to electricity and then again to light, decreasing total efficiency. This phenomenon limits the installation of the system but on other hand it facilitates CPV building integration. Fig. 41 shows a possible implementation in which a parquet of lenses can be concentrated in photovoltaic cells and optical fibers. The improvement achieved by this approach is shown in Fig. 42. On the left side, there is a classic multi-junction highly efficient CPV system that is connected to a conventional fluorescent lamp to obtain $1200 \mathrm{~lm}$. However, on the right side, if a part (25\%) of the sunlight is oriented to a light guide that transports $50 \%$ of the total, it can obtained the initial $1200 \mathrm{~lm}$, plus the rest of the $75 \%$ of the original electricity [78].

\section{Fig. 41}

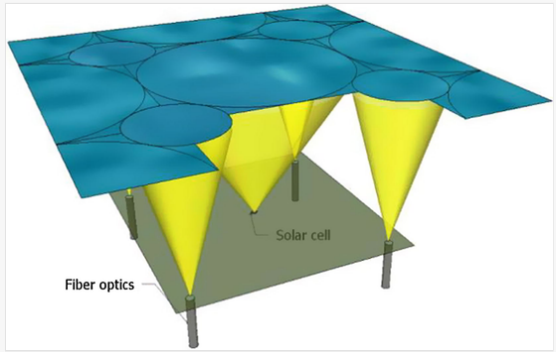

Artistic impression of an adaptation of optical fiber in CPV bi-concentration parquet of lenses [79].

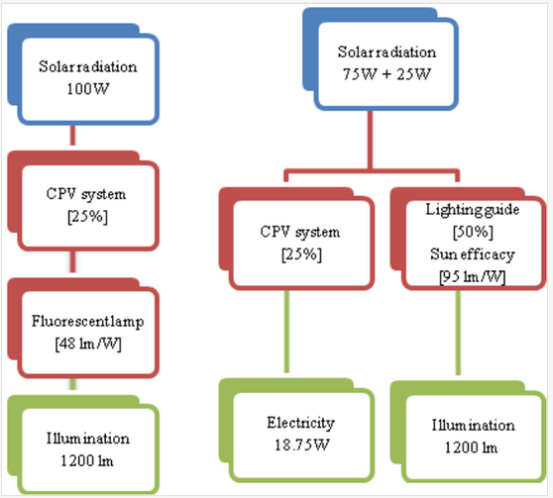

Artistic impression of an adaptation of optical fiber in CPV bi-concentration parquet of lenses [79].

A novel concentrating photovoltaic/daylighting window is proposed and validated experimentally by Xuan et al. [80]. By ray-tracing simulation and indoor experiment, the optical performance is identified. Furthermore, an outdoor experiment is conducted at a typical office building under various installation angles $\left(0^{\circ}, 10^{\circ}, 20^{\circ}, 30^{\circ}, 40^{\circ}\right)$, window-to-ceiling ratios $(50 \%, 75 \%$ and $100 \%)$ and under different climate conditions for analyzing annual daylight performance. The results show that the deviation between the experimental and simulation results is as low as $8.7 \%$, which is indicated by the coefficient of variation of the root mean squared error. Xuan et al. [81] also propose an asymmetric concentrator-PV (ACPV) type window for the building south wall. An arrangement optimization strategy by setting gaps between each ACPV array is presented to reduce the shading effect between each concentrator array. The simulation results 
show that the asymmetric concentrator can attain a large acceptance range of $10^{\circ}-85^{\circ}$ while maintaining high optical efficiency and the asymmetric concentrator-PV type window can achieve the daylighting efficiency of $4.0 \%$ to $21.8 \%$.

\subsection{Building integrated concentrating solar thermal/daylighting (BISCT/D)}

\subsubsection{The demand for BISCT/D}

The visual and thermal comfort are crucial issues because they are related to economic and environmental factors, at the same time the comfort also affects occupants' well being and productivity in a building [82]. Due to the limited envelope area of the building, the acquisition of thermal energy will inevitably affect the daylighting of the building and the daylighting also affects the heat and cold load of building. For example, in summer, reducing indoor lighting will reduce the cold load of the building; in winter, increasing indoor lighting will reduce the indoor heat load. Finally, the daylighting and temperature inside the building will affect the indoor building environment. An energy sufficient and visual comfortable daylighting solution should balance among the harvesting of natural light, prevention of heat gains and control of discomfort glare [83].

\subsubsection{Types/Applications/Structures of BICST/D}

Ulavi et al. [84] has conducted a study on a hybrid "solar window" that gives heating with daylighting. In their work a hybrid "solar window" which integrated naturally with building is proposed and analyzed based on the splitting the spectral band. This window does multiple functions such as it illuminates the indoor space, produces heat energy that can be further used for water or space heating. It can also be used to control heat gains through the window. Fig. 43 shows the design of that window in the building.

\section{Fig. 43}

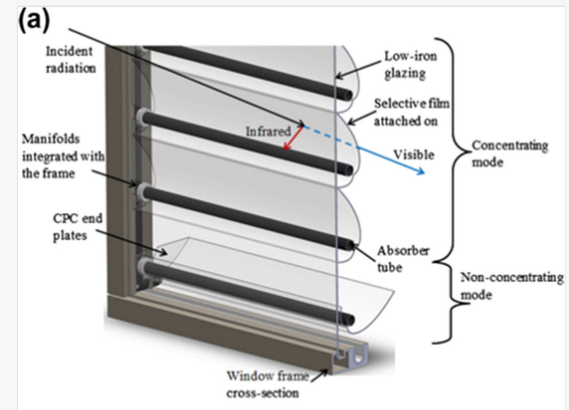

(b)

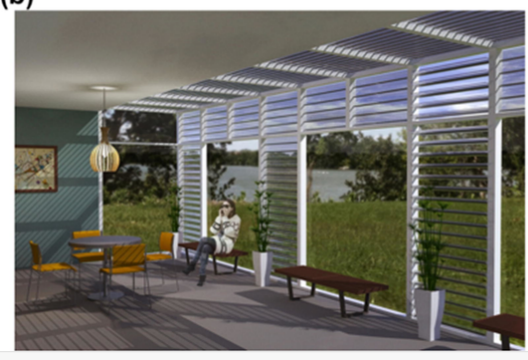

(a) Design concept for the hybrid solar window; (b) A visual rendering of the exterior and interior appearance of a building facade employing hybrid solar windows and skylights. [Rendering made by Becky Alexander, School of Architecture, University of Minnesota] [83].

They modeled a solar window to identify the influence of the CPC geometry on the heating and lighting performance. Monte Carlo Ray-Tracing (MCRT) approach is used to analyze the behavior of a film of selected wavelength. The MCRT governs the spectral and energy division between thermal module and the daylighting area as a function of direction and wavelength of rays. These results serve to forecast the yearly thermal performance of system, as well as the lighting and thermal insulation properties of window [84]. In short, a double-glazed window has better lighting and thermal insulation properties than colored, clear or reflective glazing and is similar to double glazed window having single low-e coating. The design of window has extra flexibility of working in nonconcentrated mode to get greater thermal gain for passive heating if needed. This unique idea of solar window is presented for the first time that uses film of selective wavelength to divide incoming rays into different spectral bands for heating and lighting purposes. This hybrid window is very adaptable with respect to its function and utilization. It uses the portion of incident radiation that is not used for lighting to produce heat energy for use in water heating, etc. Thermal performance of this window is strongly dependent upon the geometry of CPC. This window can also be used in non-concentration mode where it can achieve higher heating. This proposed window design can possibly replace the glazing systems [84].

\subsection{Building integrated concentrating photovoltaic/thermal/daylighting (BICPV/T/D)}

\subsubsection{The demand for BICPV/T/D}

The combination of daylighting, PV and thermal energy can further improve the utilization efficiency of solar energy. For buildings, the effective combination of the three can further reduce the external energy demand of buildings, so as to maximize self-sufficiency. At the same time, there is a certain coupling relationship 
among the three, and the proportion of them should be optimized according to the actual demand of the building.

\subsubsection{Types/Applications/Structures of BICPV/T/D}

Feng et al. [50] suggested a new transparent roof based on the solid CPC-PV/T/D (Photovoltaic/Thermal/Daylighting) system. In this system, green building design uses solar PV/T/D system. Excessive light control at noon is achieved with the PV/T/D, and thermal environment is adjustable in the building. These features make the system a highly efficient user of the solar energy in modern architecture. The visual comfort of the buildings for occupants can be increased by this kind of roofs; unlike transparent roofs, by employing this roof, the temperature of the building interior is protected from overheating at noon time. An experimental system for PV/T/D was developed, and photovoltaic efficiency, light transmission, and air heating were tested in outdoor conditions. Fig. 44 shows the structure of this PV/T/D. The system consists of the top cover, the bottom cover and the side plates. All these parts are made of PMMA (polymethyl methacrylate). The top cover is constructed using a rigid CPC and the PV cell is glued to this solid CPC. Any change in angles of light causes change in light transmission. The thickness of the PV/T/D lower cover is $3 \mathrm{~mm}$ in which 900 holes are located. The width and length of the PV/T/D system are $300 \mathrm{~mm}$. Fig. 45 shows system dimensions [50]. When light hits a solid CPC at various angles of incidence, it reflects and refract across the various surfaces of CPC, and the path of light is illustrated in Fig. 2. For the dielectric CPC, the escape sun rays allow the function of illuminating the building [50].

\section{Fig. 44}

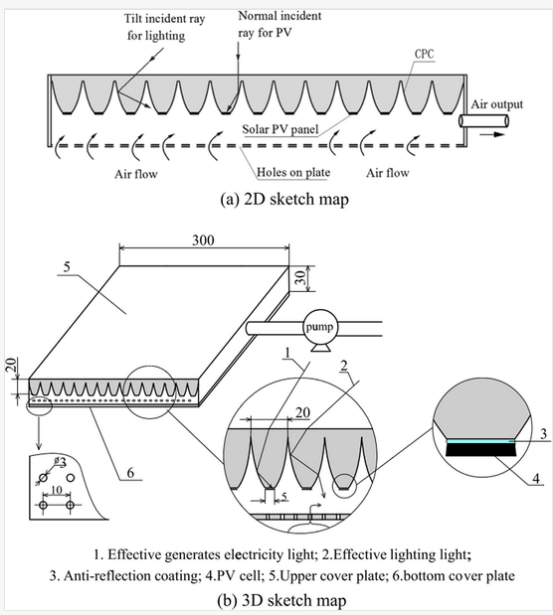

The working principle of the PV/T/D device [50]

\section{Fig. 45}

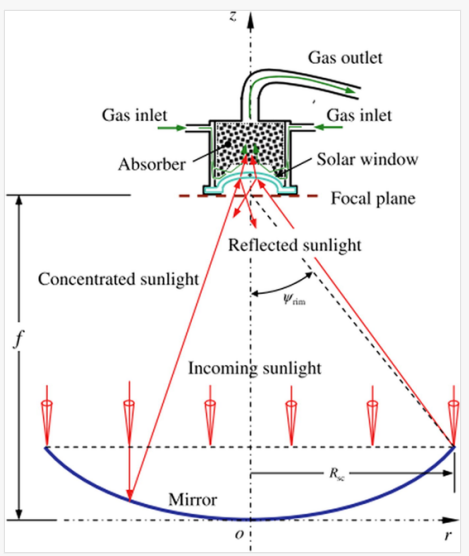

Section drawing of the integrated sunlight transferring model [84].

This design of the building integrated concentrating PV/T/D can attain outstanding light control at noon time, thus improving the thermal atmosphere in room. It could have a greater utilization of energy in modern construction. The CPV/T/ D roof design should be set in the east-west direction if users care more of the internal temperature setting during summer and winter. Ray tracking simulation is done to track the path of light with various angles of incidence. With increasing angle of incidence, optical efficiency is reduced almost linearly. Changing the transmission curve shows a trend that is rapid before it slows down. Transmission curve changing point appears at about 30 degrees when transmittance can reach $70 \%$. While the CPV /T/D system has no apparent impact on the intensity of light entering the room in morning time and afternoon time, while significantly decreasing the intensity of the light at noon time, it may enhance the condition of uneven lighting in the room in one day. Simultaneously, the CPV/T/D can provide both hot air and electricity with excessive light. In addition, 
$\mathrm{CPV} / \mathrm{T} / \mathrm{D}$ cost is in the price range of conventional materials like conventional glass roofing. So, the new roof is improved as compared to traditional glass roof, and it also has a wide range of applications [50].

Dai et al. [85] studied an integrated sunlight transfer model that was constructed by a dish concentrator connected to convex window. The performance of window transmission was also investigated by Monte Carlo ray tracing (MCRTM) approach. Using this system, a large number of sun rays were traced from the dish to window by the MCRTM tracing method to obtain statistical results. The effect of geometries and material use on performance of window transmission were also discussed. Fig. 45 demonstrates an integrated model of sunlight transfer in combination with a dish and a convex window. Gas with high pressure passes through receiver to transfer the concentrated energy of radiation. In order to survive the internal receiver pressure, the convex surface of solar window points to cavity. On the other hand, the lower surface of window is set to the focal plane of dish. The light reaches at aperture and then centered on dish. When the light hits the window, then a part of the light reflects, the part is absorbed, and the part is transmitted to the receiver cavity [85]. Concentrated light effects depend on geometry, tracking error in dish and slope errors. For instances, the impact of window geometry (e.g. Semi-Minor axis and Window Thickness) on transmission performance is negligible. The geometry of window is mostly determined by the requirements of mechanical strength [85]. The absorption coefficient and refractive index of sapphire are higher than the quartz glass index, and the transmissibility of the sapphire window is about $12.0 \%$ less than quartz glass window. Slope errors and errors in angle of tracking result in deviation of light concentration. The input angle between incoming sunlight and normal window direction can be increased by increasing the inclination errors and the errors in the tracking angle. They have shown that the slope error reduction and the tracking error angle are useful for improving the transmission characteristics of the solar window [85].

\section{Prospects/Directions/Policies around the world}

It was predicted by the International Energy Agency (IEA) that building integrated solar PV technology that can be implemented in all types of buildings would be a future potential [19]. As it is revealed by a report conducted by IEA about the prospects of the building integrated PV systems (BIPV) in fourteen countries, a potential BIPV area is about 23 billion $\mathrm{m}^{2}$ that can produce about $3 \mathrm{pWh}$ electricity annually [86]. Oliver and Jackson concluded in their study that the BIPV systems have the following three major advantages in comparison to the centralized PV plants [8]:

(1) There is no requirement of land for installation, fence at site, site access road and few other supportive parts;

(2) The electricity conveyance and distribution losses can be reduced due to on-site usage in case of BIPV systems;

(3) In BIPV systems, the building parts like roof, window and facade can be substituted which further reduces the overall cost of BIPV systems.

It has been validated that besides the space heating, air-conditioning and lighting, the water heating energy demands account for more than $20 \%$ of domestic energy use in the developed countries such as the United States [87]. In this regard, building integrated thermal systems with the use of the water as the working fluid have shown the potential to cover $70-90 \%$ of water heating demand in the buildings; thus, makes them the best option to reduce domestic energy use.

From the current statistical data, the world capacity of the solar water heating usage in 2010 is around $160 \mathrm{GW}$, and this value jumps to $185 \mathrm{GW}$ at the beginning of 2011 [88]. With China occupying the largest share in the solar water heating market, large usage has also been witnessed in European Union, India, Japan and Brazil. However, there were only 100 such industrial scale projects working in 2010 despite the large worldwide possibilities for significant growth in the household water heating market and in industries.

Energy Information Administration (EIA) estimated that the use of electric power for light purpose in domestic \& commercial areas is 279 billion kWh in 2016 , that was about $10 \%$ of total use by these two sectors and about $7 \%$ of total electric power use in the US [49].

The efficient application of daylighting for replacement of artificial lighting to make more visually comfortable rooms is another benefit for modern buildings. Furthermore, it was reported by Wong that the artificial lighting has negative effect on human health [72]. On the other hand, natural light offers many advantages to health and, it helps in curing few medical ailments [73]. Moreover, natural light also helps in coping with psychological sadness which is related to the seasonal effective disorder [74].

The research study [89] concluded that there is large demand for wind energy, PV energy and heat energy, and simultaneously, there is need to reduce the energy demands of buildings to attain feasible solutions for $100 \%$ renewable energy usage to produce heat energy and electricity in Germany in 2050 .

In the Thirteenth Five-year Plan for the development of strategic emerging industries of China, it is highly encouraged to develop the renewable technology especially the high-performance solar utilization technologies for building application. Since 2010, the EU has implemented many strategies to encourage the usage of alternatives of energy sources which are being used in buildings for water heating, cooling, room heating and electricity [90]. And legal frame of EU further proposes the idea of Nearly Zero Energy Buildings (NZEB) and they claimed that it should be considered from January 1 st, 2018 for any investment, and from 2021 for any building construction.

For the European Union (EU), it was stated by directive 2010/31/EU that all public buildings which are constructed after December 31 st, 2018 must be nearly zero energy related. It was also stated by directive 2010/31/EU that all other new constructed buildings should be nearly zero energy related by the end of December 31st, 2020 [90]. This shows that the newly constructed buildings must adopt active renewable energy technologies to produce their own energy for use and they must not be totally reliant on the grid-based electricity produced from the traditional fossil fuel resources. Using the buildings' own structure reasonably to host renewable energy generation device such as PV, PV or CPV, CPT panels via BIPV, BIPT or BICPV, BICPT has huge potential to facilitate this transition and enable the organizations to comply with directive 2010/31/EU. However, according to the report entitled Perspectives for the Energy Transition Investment Needs for a Low-Carbon Energy System formulated by the IEA in 2017, a significant rise in usage of low carbon approaches in construction field is required to accomplish the goals of Paris agreement [78]. This report also analyzed the challenges in existing housing stock and concluded that $70 \%$ of the current infrastructure will present in 2050 and a robust policy is needed to cope with the limitations in many countries [78]. 
In this regards, Building Integrated Solar Concentrating Systems maybe other solutions to be used on the buildings. For the future net zero energy related buildings, the requirements are not only the water heating and electric energy, but it also requires focusing on space heating, cooling, refrigeration and dehumidification that requires high quality heating source, especially in winter season [19]. But it may be difficult to fulfil the aforementioned demands because of low intensity radiation; therefore, the building integrated solar concentrating systems are found to be effective against any such constraints [91]. At beginning, the use of concentrators is mainly to decrease the overall cost of the systems as the price of the solar cells are very high. But even with the reduction in PV price and enhancement in their performance with time, the low concentration photovoltaic approach is still a practicable and cost-effective way in engineering field as it is more environment friendly and economical in comparison to PV approach [92]. Moreover, the concentrators makes use of the high transmittance and strong mechanical property such as PMMA, which means that it can also act as the supportive structure for building integration and provide better aesthetic values like double glazing windows, sky lights and solar blinds [93-95].

\section{Conclusion}

With the development of the energy saving buildings, the solar energy integrated with buildings has attracted a lot more attentions. Solar concentrating systems integrated with buildings is different from the common solar systems integrated with buildings because of the special structure. At the same time, it can obtain the advantage of the solar concentrators.

In this paper, building integrated solar concentrating systems have been introduced, analyzed and classified based on different functions, such as Building Integrated Concentrating Photovoltaic (BICPV), Building Integrated Concentrating Solar Thermal (BICST), Building Integrated Solar Daylighting (BICSD), Building Integrated Concentrating Photovoltaic/Thermal (BICPV/T), Building Integrated Concentrating Photovoltaic/Daylighting (BICPV/D), Building Integrated Concentrating Solar Thermal/Daylighting (BICST/D), and Building Integrated Concentrating Photovoltaic/Thermal/Daylighting (BICPV/T/D) systems. The demands of these systems to be used on the buildings are stated in detail. The types, structures and application of the building integrated concentrating systems is reviewed, introduced and concluded. Finally, the prospects, directions and policies around the world for the development of the building integrated concentrating systems are investigated and concluded in the last section.

Unlike the previous published review articles about the low concentration concentrators, this paper focused on the ones that are suitable for building applications and made a classification based on this criterion, i.e. BICPV, BICST, BICSD and the combination of them as BICPV/T, BICPV/D, BICST/D and BICPV/T/D. This paper also provided many valuable information for the actual engineering of building integrated concentrating devices. For example,

- Solar concentrators with PV can not only save lots of PV materials but also replace the partial building envelops, so it can save the cost.

- Solar concentrators with the thermal output can obtain higher temperature which will provide the possibility for more thermal utilization of the buildings.

- Solar concentrators with the daylighting utilization can be optimized based on more smart designs, which will provide more comfortable daylighting for buildings.

\section{Uncited reference}

[96].

\section{Declaration of Competing Interest}

The author declare that there is no conflict of interest.

\section{Acknowledgment}

This study was sponsored by the Project of EU Marie Curie International incoming Fellowships Program (745614).

\section{References}

The corrections made in this section will be reviewed and approved by journal production editor.

[1] Singh B, Othman MY. A review on photovoltaic thermal collectors. J Renew Sustain Energy 2009;1:62702. doi:10.1063/1.3266963.

[2] LA Almonacid G. Truncated compound parabolic concentrators. EC Photovolt Sol Conf 1988;294-298.

[3] Bowden S, Wenham SR, Green MA. Application of static concentrators to photovoltaic roof tiles. Prog Photovoltaics Res Appl 1995;3:413423. doi:10.1002/pip.4670030606.

[4] Sarmah N, Mallick TK. Design, fabrication and outdoor performance analysis of a low concentrating photovoltaic system. Sol Energy 2015;112:361-372. doi:10.1016/j.solener.2014.12.019.

[5] Aldegheri F, Baricordi S, Bernardoni P, Brocato M, Calabrese G, Guidi V, et al. Building integrated low concentration solar system for a selfsustainable Mediterranean villa: the Astonyshine house. Energy Build 2014;77:355-363. doi:10.1016/j.enbuild.2014.03.058. 
[6] Marín-Sáez J, Chemisana D, Atencia J, Collados M-V. Outdoor performance evaluation of a holographic solar concentrator optimized for building integration. Appl Energy 2019;250:1073-1084. doi:10.1016/j.apenergy.2019.05.075.

[7] Sellami N, Mallick TK. Design of nonimaging static solar concentrator for window integrated photovoltaic. AIP Conf Proc 2012;1477:106109. doi:10.1063/1.4753845.

[8] Oliver M, Jackson T. Energy and economic evaluation of building-integrated photovoltaics. Energy 2001;26:431-439. doi:10.1016/S03605442(01)00009-3.

[9] Park KE, Kang GH, Kim HI, Yu GJ, Kim JT. Analysis of thermal and electrical performance of semi-transparent photovoltaic (PV) module. Energy 2010;35:2681-2687. doi:10.1016/j.energy.2009.07.019.

[10] Chemisana D. Building integrated concentrating photovoltaics: a review. Renew Sustain Energy Rev 2011;15:603-611. doi:10.1016/j.rser.2010.07.017.

[11] Charalambous PG, Maidment GG, Kalogirou SA, Yiakoumetti K. Photovoltaic thermal (PV/T) collectors: a review. Appl Therm Eng 2007;27:275-286. doi:10.1016/j.applthermaleng.2006.06.007.

[12] Day J, Senthilarasu S, Mallick TK. Enhanced efficiency for building integrated concentrator photovoltaic modules based on rare earth doped optics. Sol Energy Mater Sol Cells 2019;199:83-90. doi:10.1016/j.solmat.2019.04.013.

[13] Chemisana D, Tripanagnostopoulos Y, Lamnatou C, Souliotis M, Rosell JI, Barrau J. Tilt optimization of a building integrated solar concentrating unit. AIP Conf Proc 2012;1477:217-220. doi:10.1063/1.4753872.

[14] Gite SS, Walke PV. Photovoltaic cell with concentrating collector - a review. Int J Eng Res Technol 2013;2:1-9.

[15] Mallick T, Eames P. Design and fabrication of low concentrating second generation PRIDE concentrator. Sol Energy Mater Sol Cells 2007;91:597-608. doi:10.1016/j.solmat.2006.11.016.

[16] Yoshioka K, Endoh K, Kobayashi M, Suzuki A, Saitoh T. Design and properties of a refractive static concentrator module. Sol Energy Mater Sol Cells 1994;34:125-131. doi:10.1016/0927-0248(94)90032-9.

[17] Yoshioka K, Kobayashi M, Suzuki A, Endoh K, Ohe N, Saitoh T. An optimum design and properties of a static concentrator with a nonimaging lens. In: Proc. 1994 IEEE 1st World Conf. Photovolt. Energy Convers. - WCPEC (A Jt. Conf. PVSC, PVSEC PSEC), vol. 1, IEEE; n.d., p. 1119-22. doi: 10.1109/WCPEC.1994.520158.

[18] Yoshioka K, Goma S, Hayakawa S, Saitoh T. Preparation and properties of an experimental static concentrator with a new three-dimensional lens. Prog Photovoltaics Res Appl 1997;5:139-145. doi:10.1002/(SICI)1099-159X(199703/04)5:2<139::AID-PIP161>3.0.CO;2-2.

[19] Muhammad-Sukki F, Abu-Bakar SH, Ramirez-Iniguez R, McMeekin SG, Stewart BG, Sarmah N, et al. Mirror symmetrical dielectric totally internally reflecting concentrator for building integrated photovoltaic systems. Appl Energy 2014;113:32-40. doi:10.1016/j.apenergy.2013.07.010.

[20] Baig H, Sellami N, Mallick TK. Performance modeling and testing of a building integrated concentrating photovoltaic (BICPV) system. Sol Energy Mater Sol Cells 2015;134:29-44. doi:10.1016/j.solmat.2014.11.019.

[21] Sarmah N, Richards BS, Mallick TK. Design, development and indoor performance analysis of a low concentrating dielectric photovoltaic module. Sol Energy 2014;103:390-401. doi:10.1016/j.solener.2014.02.029.

[22] Fernández EF, Almonacid F, Sarmah N, Rodrigo P, Mallick TK, Pérez-Higueras P. A model based on artificial neuronal network for the prediction of the maximum power of a low concentration photovoltaic module for building integration. Sol Energy 2014;100:148-158. doi:10.1016/j.solener.2013.11.036.

[23] Mammo ED, Sellami N, Mallick TK. Performance analysis of a reflective 3D crossed compound parabolic concentrating photovoltaic system for building fa??ade integration. Prog Photovoltaics Res Appl 2013;21:1095-1103. doi:10.1002/pip.2211.

[24] Sellami N, Mallick TK. Optical characterisation and optimisation of a static window integrated concentrating photovoltaic system. Sol Energy 2013;91:273-282. doi:10.1016/j.solener.2013.02.012.

[25] Mallick TK, Eames PC, Hyde TJ, Norton B. The design and experimental characterisation of an asymmetric compound parabolic photovoltaic concentrator for building façade integration in the UK. Sol Energy 2004;77:319-327. doi:10.1016/j.solener.2004.05.015.

[26] Mallick TK, Eames PC, Norton B. Non-concentrating and asymmetric compound parabolic concentrating building façade integrated photovoltaics: an experimental comparison. Sol Energy 2006;80:834-849. doi:10.1016/j.solener.2005.05.011.

[27] Sabry M, Abdel-Hadi YA, Ghitas A. PV-integrated CPC for transparent façades. Energy Build 2013;66:480-484. doi:10.1016/j.enbuild.2013.07.059. 
[28] Su Y, Pei G, Riffat SB, Huang H. A novel lens-walled compound parabolic concentrator for photovoltaic applications. J Sol Energy Eng 2012;134:21010. doi:10.1115/1.4005757.

[29] Li G. Design and development of a lens-walled compound parabolic concentrator - a review 2019;28:17-29.

[30] Li G. Design and development of a lens-walled compound parabolic concentrator - a review. J Therm Sci 2019;28:17-29. doi:10.1007/s11630-019-1083-3.

[31] Li G, Pei G, Ji J, Su Y, Zhou H, Cai J. Structure optimization and annual performance analysis of the lens-walled compound parabolic concentrator. Int J Green Energy 2016;13:944-950. doi:10.1080/15435075.2015.1109514.

[32] Li G, Pei G, Su YH, Ji J, Riffat SB. Experiment and simulation study on the flux distribution of lens-walled compound parabolic concentrator compared with mirror compound parabolic concentrator. Energy 2013;58:398-403. doi:10.1016/j.energy.2013.06.027.

[33] Li G, Su Y, Pei G, Yu X, Ji J, Riffat S. Preliminary experimental comparison of the performance of a novel lens-walled compound parabolic concentrator (CPC) with the conventional mirror and solid CPCs. Int J Green Energy 2013;10:848-859. doi:10.1080/15435075.2012.727928.

[34] Li G, Pei G, Yang M, Ji J, Su Y. Optical evaluation of a novel static incorporated compound parabolic concentrator with photovoltaic/thermal system and preliminary experiment. Energy Convers Manage 2014;85:204-211. doi:10.1016/j.enconman.2014.05.082.

[35] Xuan Q, Li G, Pei G, Ji J, Su Y. Design and optical evaluation of a novel asymmetric lens-walled compound parabolic. J Daylighting 2017;4:26-36. doi:10.15627/jd.2017.5.

[36] Xuan Q, Li G, Pei G, Ji J, Su Y, Zhao B. Optimization design and performance analysis of a novel asymmetric compound parabolic concentrator with rotation angle for building application. Sol Energy 2017;158:808-818. doi:10.1016/j.solener.2017.10.029.

[37] Li G, Xuan Q, Lu Y, Pei G, Su Y, Ji J. Numerical and lab experiment study of a novel concentrating PV with uniform flux distribution. Sol Energy Mater Sol Cells 2018;179:1-9. doi:10.1016/j.solmat.2018.02.012.

[38] Jayathissa P, Luzzatto M, Schmidli J, Hofer J, Nagy Z, Schlueter A. Optimising building net energy demand with dynamic BIPV shading. Appl Energy 2017;202:726-735. doi:10.1016/j.apenergy.2017.05.083.

[39] Powell D, Hischier I, Jayathissa P, Svetozarevic B, Schlüter A. A reflective adaptive solar façade for multi-building energy and comfort management. Energy Build 2018;177:303-315.

[40] Menoufi K, Chemisana D, Rosell JI. Life cycle assessment of a building integrated concentrated photovoltaic scheme. Appl Energy 2013;111:505-514. doi:10.1016/j.apenergy.2013.05.037.

[41] Zondag HA. Flat-plate PV-Thermal collectors and systems: a review. Renew Sustain Energy Rev 2008;12:891-959. doi:10.1016/j.rser.2005.12.012.

[42] Kumar A, Baredar P, Qureshi U. Historical and recent development of photovoltaic thermal (PVT) technologies. Renew Sustain Energy Rev 2015;42:1428-1436. doi:10.1016/j.rser.2014.11.044.

[43] Wall M, Probst MCM, Roecker C, Dubois M-C, Horvat M, Jørgensen OB, et al. achieving solar energy in architecture-IEA SHC Task 41. Energy Procedia 2012;30:1250-1260. doi:10.1016/j.egypro.2012.11.138.

[44] Xie H, Wei J, Wang Z, Yang G, Ma Q. Design and performance research on eliminating multiple reflections of solar radiation within compound parabolic concentrator (CPC) in hybrid CPV/T system. Sol Energy 2016;129:126-146. doi:10.1016/j.solener.2016.01.037.

[45] Harmim A, Merzouk M, Boukar M, Amar M. Design and experimental testing of an innovative building-integrated box type solar cooker. Sol Energy 2013;98:422-433. doi:10.1016/j.solener.2013.09.019.

[46] Xu RJ, Zhang XH, Wang RX, Xu SH, Wang HS, Experimental investigation of a solar collector integrated with a pulsating heat pipe and a compound parabolic concentrator, Energy Conversion and Management, Volume 148, 2017, Pages 68-77, ISSN 0196-8904, https://doi.org/10.1016/j.enconman.2017.04.045.

[47] Ratismith W, Inthongkhum A, Briggs J. Two non-tracking solar collectors: design criteria and performance analysis. Appl Energy 2014;131:201-210. doi:10.1016/j.apenergy.2014.06.030.

[48] Ratismith W, Favre Y, Canaff M, Briggs J. A non-tracking concentrating collector for solar thermal applications. Appl Energy 2017;200:3946. doi:10.1016/j.apenergy.2017.05.044.

[49] EIA (US Energy Information Administration). Independent statistics and analysis: how much electricity is used for lighting in the United States; 2017 n.d.

[50] Feng C, Zheng H, Wang R, Yu X, Su Y. A novel solar multifunctional PV/T/D system for green building roofs. Energy Convers Manage 2015;93:63-71. doi:10.1016/j.enconman.2015.01.001. 
[51] Chan Y-C, Tzempelikos A. Daylighting and energy analysis of multi-sectional facades. Energy Procedia 2015;78:189-194. doi:10.1016/j.egypro.2015.11.138.

[52] Zhu L, Shao Z, Sun Y, Soebarto V, Gao F, Zillante G, et al. Indoor daylight distribution in a room with integrated dynamic solar concentrating facade. Energy Build 2018;158:1-13. doi:10.1016/j.enbuild.2017.10.008.

[53] Tian M, Zhang L, Su Y, Xuan Q, Li G, Lv H. An evaluation study of miniature dielectric crossed compound parabolic concentrator (dCCPC) panel as skylights in building energy simulation. Sol Energy 2019;179:264-278. doi:10.1016/j.solener.2018.12.058.

[54] Lu W, Liu Z, Flor J-F, Wu Y, Yang M. Investigation on designed fins-enhanced phase change materials system for thermal management of a novel building integrated concentrating PV. Appl Energy 2018;225:696-709. doi:10.1016/j.apenergy.2018.05.030.

[55] Chow TT, Hand JW, Strachan PA. Building-integrated photovoltaic and thermal applications in a subtropical hotel building. Appl Therm Eng 2003;23:2035-2049. doi:10.1016/S1359-4311(03)00183-2.

[56] Anderson TN, Duke M, Morrison GL, Carson JK. Performance of a building integrated photovoltaic/thermal (BIPVT) solar collector. Sol Energy 2009;83:445-455. doi:10.1016/j.solener.2008.08.013.

[57] Hasan MA, Sumathy K. Photovoltaic thermal module concepts and their performance analysis: a review. Renew Sustain Energy Rev 2010;14:1845-1859. doi:10.1016/j.rser.2010.03.011.

[58] Agrawal B, Tiwari GN. Optimizing the energy and exergy of building integrated photovoltaic thermal (BIPVT) systems under cold climatic conditions. Appl Energy 2010;87:417-426. doi:10.1016/j.apenergy.2009.06.011.

[59] Brogren M, Karlsson B. Low-concentrating water-cooled PV-thermal hybrid systems for high latitudes. Conf. Rec. Twenty-Ninth IEEE Photovolt. Spec. Conf. 2002, IEEE; 2002, p. 1733-6. doi: 10.1109/PVSC.2002.1190956.

[60] Kribus A, Kaftori D, Mittelman G, Hirshfeld A, Flitsanov Y, Dayan A. A miniature concentrating photovoltaic and thermal system. Energy Convers Manage 2006;47:3582-3590. doi:10.1016/j.enconman.2006.01.013.

[61] Sonneveld PJ, Swinkels GLAM, van Tuijl BAJ, Janssen HJJ, Campen J, Bot GPA. Performance of a concentrated photovoltaic energy system with static linear Fresnel lenses. Sol Energy 2011;85:432-442. doi:10.1016/j.solener.2010.12.001.

[62] Chemisana D, Rosell JI. Design and optical performance of a nonimaging Fresnel transmissive concentrator for building integration applications. Energy Convers Manage 2011;52:3241-3248. doi:10.1016/j.enconman.2011.05.006.

[63] Cappelletti A, Ceccherini L, Reatti A. Integration and architectural issues of a photovoltaic / thermal linear solar concentrator. Sol Energy 2018;169:362-373. doi:10.1016/j.solener.2018.05.013.

[64] Davidsson H, Perers B, Karlsson B. Performance of a multifunctional PV/T hybrid solar window. Sol Energy 2010;84:365-372. doi:10.1016/j.solener.2009.11.006.

[65] Brogren M, Wennerberg J, Kapper R, Karlsson B. Design of concentrating elements with CIS thin-film solar cells for façade integration. Sol Energy Mater Sol Cells 2003;75:567-575. doi:10.1016/S0927-0248(02)00162-9.

[66] Gajbert H, Hall M, Karlsson B. Optimisation of reflector and module geometries for stationary, low-concentrating, façade-integrated photovoltaic systems. Sol Energy Mater Sol Cells 2007;91:1788-1799. doi:10.1016/j.solmat.2007.06.007.

[67] Abdul Hamid S, Yusof Othman M, Sopian K, Zaidi SH. An overview of photovoltaic thermal combination (PV/T combi) technology. Renew Sustain Energy Rev 2014;38:212-222. doi:10.1016/j.rser.2014.05.083.

[68] Vivar M, Everett V, Fuentes M, Thomsen E, Harvey J, Ebert M, et al. Results from the first ANU-chromasun CPV-T microconcentrator prototype in Canberra. AIP Conf Proc 2012;1477:114-117. doi:10.1063/1.4753847.

[69] Feng C, Zheng H, Wang R, Ma X. Performance investigation of a concentrating photovoltaic/thermal system with transmissive Fresnel solar concentrator. Energy Convers Manage 2016;111:401-408. doi:10.1016/j.enconman.2015.12.086.

[70] Li G, Pei G, Ji J, Yang M, Su Y, Xu N. Numerical and experimental study on a PV / T system with static miniature solar concentrator. Sol Energy 2015;120:565-574. doi:10.1016/j.solener.2015.07.046.

[71] Gu Y, Zhang X, Are J, Han M, Chen X, Yuan Y. Techno-economic analysis of a solar photovoltaic / thermal (PV / T) concentrator for building application in Sweden using Monte Carlo method. Energy Convers Manage 2018;165:8-24. doi:10.1016/j.enconman.2018.03.043.

[72] Wong IL. A review of daylighting design and implementation in buildings. Renew Sustain Energy Rev 2017;74:959-968. doi:10.1016/j.rser.2017.03.061.

[73] Hraska J. Chronobiological aspects of green buildings daylighting. Renew Energy 2015;73:109-114. doi:10.1016/j.renene.2014.06.008. 
Sapia C. Daylighting in buildings: developments of sunlight addressing by optical fiber. Sol Energy 2013;89:113-121. doi:10.1016/j.solener.2012.12.003.

[75] Yang HX, Lou CZ, Sun LL. Building-integrated photovoltaics for maximum power generation. 2008 2nd Electron. Syst. Technol. Conf., IEEE; 2008, p. 39-44. doi:10.1109/ESTC.2008.4684320.

[76] Fung TYY, Yang H. Study on thermal performance of semi-transparent building-integrated photovoltaic glazings. Energy Build 2008;40(3):341-350. doi:10.1016/j.enbuild.2007.03.002.

[77] Wu Y, Connelly K, Liu Y, Gu X, Gao Y, Chen GZ. Smart solar concentrators for building integrated photovoltaic façades. Sol Energy 2016;133:111-118. doi:10.1016/j.solener.2016.03.046.

[78] Connelly K, Wu Y, Chen J, Lei Y. Design and development of a reflective membrane for a novel Building Integrated Concentrating Photovoltaic (BICPV) “Smart Window” system. Appl Energy 2016;182:331-339. doi:10.1016/j.apenergy.2016.07.125.

[79] Núñez R, Antón I, Sala G. Hybrid lighting-CPV, a new efficient concept combining illumination with CPV. AIP Conf Proc 2012;1477:221224. doi:10.1063/1.4753873.

[80] Xuan Q, Li G, Lu Y, Zhao B, Zhao X, Pei G. Daylighting characteristics and experimental validation of a novel concentrating photovoltaic/daylighting system. Sol Energy 2019;186. pp. 264-276, ISSN 0038-092X, 10.1016/j.solener.2019.05.014.

[81] Xuan Q, Li G, Lu Y, Zhao B, Zhao X, Su Y, et al. optimization and performance analysis of an asymmetric concentrator-PV type window for the building south wall application. Sol Energy 2019;193. pp. 422-433, ISSN 0038-092X, 10.1016/j.solener.2019.09.084.

[82] M.C. Dubios, Solar Shading and Building Energy Use, Lund University, Lund, 1997 n.d.

[83] Lim Y-W, Kandar MZ, Ahmad MH, Ossen DR, Abdullah AM. Building façade design for daylighting quality in typical government office building. Build Environ 2012;57:194-204. doi:10.1016/j.buildenv.2012.04.015.

[84] Ulavi T, Hebrink T, Davidson JH. Analysis of a Hybrid Solar Window for Building Integration. Energy Procedia 2014;57:1941-1950. doi:10.1016/j.egypro.2014.10.058.

[85] Dai G-L, Xia X-L, Hou G-F. Transmission performances of solar windows exposed to concentrated sunlight. Sol Energy 2014;103:125-133. doi:10.1016/j.solener.2014.01.036.

[86] International Energy Agency (IEA), 2002. Potential for building integrated photovoltaics. Report IEA-PVPS T7-4:2002 (Summary), IEA n.d.

[87] Energy Information Administration, Energy consumption and expenditure tables of the 2005 residential energy consumption survey, EIA, Washington, DC (2005) accessed January2001. <http:www.cia.gov/emcu/recs/2005/c\&e/detailed_tables2005/c\&e.html> n.d.

[88] Renewable Energy Policy Network, Renewable2011:Global Status Report. <http://www.ren21.net/gsr>. n.d.

[89] Henning H-M, Palzer A. A comprehensive model for the German electricity and heat sector in a future energy system with a dominant contribution from renewable energy technologies_Part I: Methodology. Renew Sustain Energy Rev 2014;30:1003-1018. doi:10.1016/j.rser.2013.09.012.

[90] Parliament European. Directive 2009/28/EC of the European Parliament and of the Council of 23 April 2009. Off J Eur Union 2009;140:1662. https://doi.org/10. 3000/17252555.L_2009.140.eng n.d.

[91] IRENA, IEA. Perspectives for the energy transition investment needs for a lowcarbon energy system. IRENA report; 2017 n.d.

[92] Li G, Xuan Q, Pei G, Su Y, Lu Y, Ji J. Life-cycle assessment of a low-concentration PV module for building south wall integration in China. Appl Energy 2018;215:174-185. doi:10.1016/j.apenergy.2018.02.005.

[93] Sellami N, Mallick TK, McNeil DA. Optical characterisation of 3-D static solar concentrator. Energy Convers Manage 2012;64:579-586. doi:10.1016/j.enconman.2012.05.028.

[94] Norton B, Eames PC, Mallick TK, Huang MJ, McCormack SJ, Mondol JD, et al. Enhancing the performance of building integrated photovoltaics. Sol Energy 2011;85:1629-1664. doi:10.1016/j.solener.2009.10.004.

[95] Li G, Xuan Q, Zhao X, Pei G, Ji J, Su Y. A novel concentrating photovoltaic/daylighting control system: optical simulation and preliminary experimental analysis. Appl Energy 2018;228:1362-1372. doi:10.1016/j.apenergy.2018.07.024.

[96] Xu RJ, Zhang XH, Wang RX, Xu SH, Wang HS. Experimental investigation of a solar collector integrated with a pulsating heat pipe and a compound parabolic concentrator. Energy Convers Manage 2017;148:68-77. doi:10.1016/j.enconman.2017.04.045.

[97] Riverola A, Moreno A, Chemisana D. Performance of a dielectric PVT concentrator for building-façade integration. Opt Express 2018;26:A892. doi:10.1364/OE.26.00A892. 
[98] Corrado C, Leow SW, Osborn M, Chan E, Balaban B, Carter SA. Optimization of gain and energy conversion efficiency using front-facing photovoltaic cell luminescent solar concentratordesign. Sol Energy Mater Sol Cells 2013;111:74-81. doi:10.1016/j.solmat.2012.12.030.

[99] Zheng W, Yang L, Zhang H, You S, Zhu C. Numerical and experimental investigation on a new type of compound parabolic concentrator solar collector. Energy Convers Manage 2016;129:11-22. doi:10.1016/j.enconman.2016.10.013.

[100] Tripanagnostopoulos Y, Souliotis M, Nousia T. CPC type integrated collector storage systems. Sol Energy 2002;72:327-350. doi:10.1016/S0038-092X(02)00005-1.

[101] Souliotis M, Quinlan P, Smyth M, Tripanagnostopoulos Y, Zacharopoulos A, Ramirez M, et al. Heat retaining integrated collector storage solar water heater with asymmetric CPC reflector. Sol Energy 2011;85:2474-2487. doi:10.1016/j.solener.2011.07.005.

[102] Helal O, Chaouachi B, Gabsi S. Design and thermal performance of an ICS solar water heater based on three parabolic sections. Sol Energy 2011;85:2421-2432. doi:10.1016/j.solener.2011.06.021.

[103] Kalogirou S. Design, construction, performance evaluation and economic analysis of an integrated collector storage system. Renew Energy 1997;12:179-192. doi:10.1016/S0960-1481(97)00029-3.

[104] Xiaodi X, Hongfei Z, Kaiyan H, Zhili C, Tao T, Guo X. Experimental study on a new solar boiling water system with holistic track solar funnel concentrator. Energy 2010;35:692-697. doi:10.1016/j.energy.2009.10.033.

[105] Oommen R, Jayaraman S. Development and performance analysis of compound parabolic solar concentrators with reduced gap losses—-V" groove reflector. Renew Energy 2002;27:259-275. doi:10.1016/S0960-1481(01)00185-9.

[106] Oommen R, Jayaraman S. Development and performance analysis of compound parabolic solar concentrators with reduced gap losses oversized reflector. Energy Convers Manage 2001;42:1379-1399. doi:10.1016/S0196-8904(00)00113-8.

[107] Rönnelid M, Karlsson B. Experimental investigation of heat losses from low-concentrating non-imaging concentrators. Sol Energy 1996;57:93-109. doi:10.1016/S0038-092X(96)00061-8.

[108] Rönnelid M, Perers B, Karlsson B. Construction and testing of a large-area CPC-collector and comparison with a flat plate collector. Sol Energy 1996;57:177-184. doi:10.1016/S0038-092X(96)00062-X.

\section{Highlights}

- It summarizes the building integrated solar concentrating systems according to different functions.

- It introduces the demands, types, applications and structures of the building integrated solar concentrating systems.

- It presents prospects/directions/policies around the world towards the building integrated solar concentrating systems.

\section{Queries and Answers}

Query: Your article is registered as a regular item and is being processed for inclusion in a regular issue of the journal. If this is NOT correct and your article belongs to a Special Issue/Collection please contact

J.Shanmugam@elsevier.com immediately prior to returning your corrections.

Answer: Yes

Query: The author names have been tagged as given names and surnames (surnames are highlighted in teal color). Please confirm if they have been identified correctly.

Answer: Yes

Query: This section comprises references that occur in the reference list but not in the body of the text. Please cite each reference in the text or, alternatively, delete it. Any reference not dealt with will be retained in this section. Answer: Please delete it. And We find the reference 29 and 30 are the same. So please change the reference 30 to "Xuan Q, Li G, Lu Y, Zhao X, Su Y, Ji J, Pei G. A general optimization strategy for the annual performance 
enhancement of a solar concentrating system incorporated in the south-facing wall of a building. Indoor and Built

Environment 2019, 1420326X19878217. https://doi.org/10.1177/1420326X19878217 "

Query: Please check 'Declaration of Competing Interest' section, and correct if necessary.

Answer: Yes

Query: Have we correctly interpreted the following funding source(s) and country names you cited in your article:

Marie Curie, United Kingdom; Energy Information Administration, United States; ? /

Answer: This study was sponsored by the Project of European Union Marie Curie International incoming Fellowships

Program (745614)

Query: Please note that as the reference [10] supplied more than once, the repletion has been removed from the list.

Please check, and amend accordingly.

Answer: Yes. 